\title{
A Comparative Study of Different Granular Structures Induced from the Information Systems
}

\section{Qingzhao Kong}

Jimei University

Weihua Xu ( $\nabla$ chxuwh@gmail.com )

Southwest University

Dongxiao Zhang

Jimei University

\section{Research Article}

Keywords: Granular computing, Rough sets, Granular structure, Partition, Covering, Reduction

Posted Date: October 21st, 2021

DOl: https://doi.org/10.21203/rs.3.rs-994877/v1

License: (1) This work is licensed under a Creative Commons Attribution 4.0 International License.

Read Full License

Version of Record: A version of this preprint was published at Soft Computing on November 19th, 2021.

See the published version at https://doi.org/10.1007/s00500-021-06499-2. 


\begin{abstract}
Binary information table, multi-valued information table and set-valued information table are three kinds of information systems often encountered in information processing. For any information system, we can often induce different information granular structures, and then construct the corresponding rough set models. Generally speaking, for the same information system, three models of Pawlak rough set, covering rough set and multi-granulation rough set can be induced according to different rules. These three kinds of rough set models are effective tools for data mining and information processing. This paper studies the relationship among Pawlak rough set, covering rough set and multi granularity rough set induced in binary information table, multi-valued information table and set-valued information table, and obtains many important conclusions. The research content of this paper effectively connects the theories, methods and applications of Pawlak rough set, covering rough set and multi granularity rough set, which not only enriches the rough set theory, but also expands the application prospect of rough set.
\end{abstract}

Key words: Granular computing, Rough sets, Granular structure, Partition, Covering, Reduction

\title{
1. Introduction
}

In todays society, people are facing the problem about how to deal with large-scale complex data. In order to find useful knowledge from data conveniently and effectively, people often get a granular structure by granulating data according to the characteristics of data. Then, based on the granular structure, the corresponding granular computing model is constructed to deal with various data analysis problems. Therefore, this idea of granulating and processing the complex data is called granular computing method. In recent years, granular computing has become a popular research branch in the fields of knowledge discovery and data analysis.

In 1979, Zadeh et al.(1979) published a paper entitled fuzzy sets and information granularity, in which they first proposed the concept of information granule. Since then, people have been interested in using information granules to represent data information in information systems ( $\mathrm{Li}$ et al. 2019, $2020 \mathrm{a}, 2020 \mathrm{~b}$, Xu and Li. 2016). Therefore, a series of granular computing models are defined based on various information granules. In 1985, Hobbs (1985) discussed the decomposition and merging of granules, and how to get granules with different sizes, and proposed a model to generate granules with different sizes. In addition, in order to deal with the problem solving, the quotient space model is proposed (Zhang and Zhang 1992). The idea of quotient space theory is that different quotient spaces can be constructed for the same problem, so as to get different solutions from various angles and levels. Finally, based on these solutions, the solution of the original problem can be accurately described. Lin (2000) discussed the granular computing model in binary relation, and discusses the granular structure, granular description, and granular application. On the basis of Lin's work, Yao $(1998,2001)$ proposed the granular computing model based on neighborhood system. This model led to solve the problem of consistent classification by using the lattice composed of

\footnotetext{
${ }^{*}$ Corresponding author is W.H. Xu(E-mail: chxuwh@gmail.com).

Email addresses: kongqingzhao@163.com (Qingzhao Kong), chxuwh@gmail .com (Weihua Xu ), 149956879@qq. com (Dongxiao Zhang)
} 
all partitions and provided a new method and perspective for knowledge mining. Based on probability theory and fuzzy mathematical theory, Li et al. (1995) introduced the cloud model which can realize qualitative and quantitative mutual conversion. An and Wang et al. (2005) put forward a granular computing model based on tolerance relation. To sum up, we can see that scholars define information granules by different methods and then build corresponding granular computing models to solve various theoretical and practical problems. As a wonderful number, " 3 " plays an important role in people's daily life and work. Three-way decisions are ternary or ternary thinking, which can also be understood as a granular computing model based on three granules. By adding the "uncommitted" option to the traditional "accept" and "reject" options, Yao $(2010,2012,2016,2018)$ proposed a three-way decision model by dividing the research objects into three disjoint parts, which can effectively avoid the loss caused by the false acceptance or rejection under the uncertainty of object cognition, and improve the accuracy of decision.

When dealing with data mining and knowledge discovery with granular computing method, we find that different granular structure can be induced in the same information system. Based on these granular structures, various granular computing models can be defined to solve the practical problems. For example, Pawlak (1982) proposed the rough set model in 1982. Its essential idea is to define two exact sets (upper and lower approximation sets) to describe a set with fuzzy boundary by using a partition on the universe. Rough set model can effectively analyze data without any prior knowledge, so it has been widely concerned and studied as soon as it is proposed. In order to better describe and reflect the characteristics of data, Zakowski (1983) extended the partition of the universe to the covering in 1983, and established the covering rough set model. Covering rough set model is one of the most important models in rough set theory. Until now, it is still a hot topic to analyze data with covering rough set models (Xu and Zhang 2007, Zhu and Wang 2012, Wang et al. 2015). Sometimes, based on the different attributes of information system, we can get a serious of partitions. In order to integrate these partitions to obtain the required knowledge, Qian et al. (2010 a,b) established a multi-granulation rough set model based on multiple partitions. This multi-granulation rough set model provides a very effective method to solve the problem of information fusion (Li 2016, Xu and Guo 2016, Xu and Yu 2017, Kong and Xu 2019, Sun et al. 2019, Yang et al. 2020). In particular, many scholars have extended multiple partitions to multiple coverings, and further proposed and studied the multi-granulation rough set models based on multiple coverings (Lin ea al. 2013, Liu et al. 2014, Qian et al. 2014, Zhang and Kong 2016, Kong and Xu 2018).

Although rough set theory has been widely studied, there are still many deficiencies to be solved. On the basis of previous studies, this paper attempts to discuss the following problems. For instance, through the above analysis, four kinds of granular structures can be induced by an information system, which are granular structures based on one partition, one covering, multiple partitions and multiple coverings, respectively. Furthermore, the Pawlak rough set model, the covering rough set model, the multi- granulation rough set model based on multiple partitions and the multi-granulation rough set model based on multiple coverings are established, respectively. These four kinds of granular structures and rough set models have their own advantages and disadvantages in solving practical problems. So we naturally raise a question: how many kinds of granular structures can be induced from the same information system? At the same time, what is the relationship among the rough set models based on these granular structures? Finally, as the reduction theory is a very important research topic of granular computing method (Kong et al. 2020, Long et al. 2020, Wang et al. 2020), then what are the similarities and differences of the reduction theories of these granular structures? If these three questions can be answered well, we would have a deep understanding of the interrelationship between the granular structures and the rough set models. The purpose of this paper is to highlight the advantages of each granular structure and granular computing model and overcome their own shortcomings. When we analyze data and discover knowledge, three kinds of information systems are often involved, which are the binary information system, the multi-valued information system and the set-valued information system, respectively. Based on the data characteristics of these three kinds of information systems, there will be many differences in the information granules and granular structures induced from these information systems. The rough set models based on these granular structures are also different. Finally, there are many similarities and differences among the reduction theories of these granular structures. In this paper, the induced granular structures in binary information system, multivalued information system and set-valued information system, the relationship among the rough set models based on these granular structures, and the similarities and differences among the reduction theories based on these granular structures are deeply studied, respectively.

The rest of this paper is organized as follows. In Section 2, the concepts of information granules and four kinds 
of granular structures induced by information system are reviewed at the beginning. And then the rough set models generated by these four kinds of granular structure are introduced. Finally, the concepts of reduction related to these four kinds of granular structures are shown. In Section 3, four kinds of granular structures induced by binary information system are studied. At the same time, the relationship among the rough set models related to these granular structures is discussed systematically. Then the reduction theories among the four kinds of granular structures are compared. In Section 4, three kinds of granular structures induced by multi-valued information system are studied. Then the rough set models and reductions based on these granular structures are comparatively studied. In Section 5 , the granular structures induced by set-valued information system are studied. Then, the corresponding rough set models and reduction theories are further comparatively discussed. Section 6 gives a brief review and summary of this paper and introduces the follow-up research works.

\section{Preliminaries}

Generally speaking, an information table or an information system can be defined by a tuple as follows (Pawlak 1981): $I=\left(O B, A T,\left\{V_{a} \mid a \in A T\right\},\left\{f_{a} \mid a \in A T\right\}\right)$, where the universe $O B=\left\{x_{1}, x_{2}, \cdots, x_{n}\right\}$ is a nonempty finite set; $A T=\left\{a_{1}, a_{2}, \cdots, a_{m}\right\}$ is a nonempty attribute set; $V=\cup_{a_{i} \in A T} V_{a_{i}}, V_{a_{i}}=\left\{v_{a_{i} 1}, v_{a_{i} 2}, \cdots, v_{a_{i} l_{i}}\right\}$ is the domain of attribute $a_{i} ; f_{a_{i}}: O B \longrightarrow V_{a_{i}}$ is an information function. We use $f_{a_{i}}(x)$ to denote the value of object $x$ on attribute $a_{i}, i=1,2, \cdots, m$.

\section{1. granules and granular structures induced by the information system}

Based on different data characteristics and considerations, multiple granular structures are often induced from the same information system. Then, according to these granular structures, the corresponding rough set models are established to deal with the data problems in various environments. Next, the concept of elementary information granules in information system is introduced, and then several kinds of granular structures induced from the same information system are shown.

Definition 2.1 Suppose that $I=\left(O B, A T,\left\{V_{a} \mid a \in A T\right\},\left\{f_{a} \mid a \in A T\right\}\right)$ is an information system. $g_{v_{a_{j} j}}^{a_{i}}=\left\{x \in O B \mid v_{a_{i} j} \in\right.$ $\left.f_{a_{i}}(x)\right\}$ is called an elementary information granule with respect to $a_{i}$ and $v_{a_{i} j}, i=1,2, \cdots, m$ and $j=1,2, \cdots, l_{i}$.

Definition 2.2 Suppose that $I=\left(O B, A T,\left\{V_{a} \mid a \in A T\right\},\left\{f_{a} \mid a \in A T\right\}\right)$ is an information system. $\mathcal{P}_{A T}=\left\{g_{1}, g_{2}, \cdots, g_{s}\right\}$ is called a partition of $O B$ with respect to $A T$, if (1) for any $g \in \mathcal{P}_{A T}$ and any $x, y \in g, f_{a_{i}}(x)=f_{a_{i}}(y), i=1,2, \cdots, m$.; (2) for any $g^{\prime}, g^{\prime \prime} \in \mathcal{P}_{A T}$, any $x \in g^{\prime}$ and any $y \in g^{\prime \prime}$, there exists $a \in A T$ such that $f_{a}(x) \neq f_{a}(y)$; (3) $\cup_{i=1}^{s} g_{i}=O B$.

Definition 2.3 Suppose that $I=\left(O B, A T,\left\{V_{a} \mid a \in A T\right\},\left\{f_{a} \mid a \in A T\right\}\right)$ is an information system. $C_{A T}$ is called a covering of $O B$ with respect to $A T$, if (1) $C_{A T}$ is a family of nonempty subsets of $O B$; (2) $\cup C_{A T}=O B$.

Based on any attribute $a$ in an information system, a partition $\mathcal{P}_{a}$ of $O B$ can often be induced. In this way, $m$ partitions $\mathcal{P}_{a_{1}}, \mathcal{P}_{a_{2}}, \cdots, \mathcal{P}_{a_{m}}$ of $O B$ can be developed according to the attribute set $A T=\left\{a_{1}, a_{2}, \cdots, a_{m}\right\}$. Then a multi-partition granular structure $\mathbb{P}_{A T}=\left\{\mathcal{P}_{a_{1}}, \mathcal{P}_{a_{2}}, \cdots, \mathcal{P}_{a_{m}}\right\}$ will be developed.

Definition 2.4 Suppose that $I=\left(O B, A T,\left\{V_{a} \mid a \in A T\right\},\left\{f_{a} \mid a \in A T\right\}\right)$ is an information system. $\mathbb{P}_{A T}=\left\{\mathcal{P}_{a_{1}}, \mathcal{P}_{a_{2}}, \cdots, \mathcal{P}_{a_{m}}\right\}$ is called a multi-partition of $O B$ with respect to $A T$, if for any $\mathcal{P}_{a} \in \mathbb{P}_{A T}, \mathcal{P}_{a}$ is a partition of $O B$.

For any attribute $a$ in an information system, sometimes a covering $C_{a}$ of $O B$ will be induced. Then, $m$ coverings $C_{a_{1}}, C_{a_{2}}, \cdots, C_{a_{m}}$ of $O B$ can be developed according to the attribute set $A T=\left\{a_{1}, a_{2}, \cdots, a_{m}\right\}$. Then a multi-covering granular structure $\mathbb{C}_{A T}=\left\{C_{a_{1}}, C_{a_{2}}, \cdots, C_{a_{m}}\right\}$ will be built.

Definition 2.5 Suppose that $I=\left(O B, A T,\left\{V_{a} \mid a \in A T\right\},\left\{f_{a} \mid a \in A T\right\}\right)$ is a set-valued information system. $\mathbb{C}_{A T}=$ $\left\{C_{a_{1}}, C_{a_{2}}, \cdots, C_{a_{m}}\right\}$ is called a multi-covering of $O B$ with respect to $A T$, if for any $C_{a} \in \mathbb{C}_{A T}, C_{a}$ is a covering of $O B$.

\subsection{Rough set models based on different granular structures}

For a granular structure, a rough set model can be proposed by defining the lower and upper approximation operators. In this subsection, four kinds of rough set models are reviewed in turn: Pawlak rough set model, covering rough set model, multi-granulation rough set model based on multiple partitions, and multi-granulation rough set model based on multiple coverings. 
Definition 2.6 Suppose that $I=\left(O B, A T,\left\{V_{a} \mid a \in A T\right\},\left\{f_{a} \mid a \in A T\right\}\right)$ is an information system and $\mathcal{P}_{A T}$ is a partition of $O B$ with respect to $A T$. For any $X \subseteq O B$,

$$
\begin{aligned}
& \overline{a p r}_{\mathcal{P}_{A T}}(X)=\cup\left\{P \in \mathcal{P}_{A T} \mid P \subseteq X\right\}, \\
& \overline{a p r}_{\mathcal{P}_{A T}}(X)=\cup\left\{P \in \mathcal{P}_{A T} \mid P \cap X \neq \emptyset\right\}
\end{aligned}
$$

are called the lower and upper approximations of $X$ with respect to the partition $\mathcal{P}_{A T}$.

In 1983, Zakowski (1983) first proposed the lower and upper approximation operators in an information system. Obviously, covering rough set model is a direct extension of Pawlak rough set model.

Definition 2.7 Suppose that $I=\left(O B, A T,\left\{V_{a} \mid a \in A T\right\},\left\{f_{a} \mid a \in A T\right\}\right)$ is an information system and $C_{A T}$ is a covering of $O B$ with respect to $A T$. For any $X \subseteq O B$,

$$
\begin{aligned}
& \operatorname{apr}_{C_{A T}}(X)=\cup\left\{K \in C_{A T} \mid K \subseteq X\right\}, \\
& \overline{a p r}_{C_{A T}}(X)=\sim \underline{\operatorname{apr}}_{C_{A T}}(\sim X)
\end{aligned}
$$

are called the lower and upper approximations of $X$ with respect to the covering $C_{A T}$.

Different from Pawlak rough sets based on single equivalence relation, Qian et al. (2010a,b) proposed two rough set models called the optimistic and pessimistic multi-granulation rough sets by using multiple equivalence relations.

Definition 2.8 Suppose that $I=\left(O B, A T,\left\{V_{a} \mid a \in A T\right\},\left\{f_{a} \mid a \in A T\right\}\right)$ is an information system and $\mathbb{P}_{A T}=\left\{\mathcal{P}_{a_{1}}, \mathcal{P}_{a_{2}}, \cdots, \mathcal{P}_{a_{m}}\right\}$ is a family of the partitions of $O B$ with respect to $A T$. For any $X \subseteq O B$,

$$
\begin{aligned}
& \left.\left.\underline{\operatorname{apr}_{\mathbb{P}_{A T}}^{O}}(X)=\cup\left\{x \in O B \mid\left(x \in P_{1}\left(\in \mathcal{P}_{a_{1}}\right) \subseteq X\right) \vee\left(x \in P_{2}\left(\in \mathcal{P}_{a_{2}}\right) \subseteq X\right)\right) \vee \cdots \vee\left(x \in P_{m}\left(\in \mathcal{P}_{a_{m}}\right) \subseteq X\right)\right)\right\}, \\
& \overline{a p r}_{\mathbb{P}_{A T}}^{O}(X)=\sim \operatorname{apr}_{\mathbb{P}_{A T}}^{O}(\sim X)
\end{aligned}
$$

are called the optimistic lower and upper approximations of $X$ with respect to the family of the partitions $\mathbb{P}_{A T}$.

Definition 2.9 Suppose that $I=\left(O B, A T,\left\{V_{a} \mid a \in A T\right\},\left\{f_{a} \mid a \in A T\right\}\right)$ is an information system and $\mathbb{P}_{A T}=\left\{\mathcal{P}_{1}, \mathcal{P}_{2}, \cdots, \mathcal{P}_{l}\right\}$ is a family of the partitions of $O B$ with respect to $A T$. For any $X \subseteq O B$,

$$
\begin{aligned}
& \operatorname{apr}_{\mathbb{P}_{A T}^{P}}^{P}(X)=\cup\left\{x \in O B \mid\left(x \in P_{1}\left(\in \mathcal{P}_{a_{1}}\right) \subseteq X\right) \wedge\left(x \in P_{2}\left(\in \mathcal{P}_{a_{2}}\right) \subseteq X\right) \wedge \cdots \wedge\left(x \in P_{m}\left(\in \mathcal{P}_{a_{m}}\right) \subseteq X\right)\right\}, \\
& \overline{\operatorname{apr}}_{\mathbb{P}_{A T}}^{P}(X)=\sim \operatorname{apr}_{\mathbb{P}_{A T}^{P}}^{P}(\sim X)
\end{aligned}
$$

are called the pessimistic lower and upper approximations of $X$ with respect to the family of the partitions $\mathbb{P}_{A T}$.

Multi-granulation rough set model based on multiple coverings is proposed in recent years. The three kinds of rough set models mentioned above can be regarded as its special cases.

Definition 2.10 Suppose that $I=\left(O B, A T,\left\{V_{a} \mid a \in A T\right\},\left\{f_{a} \mid a \in A T\right\}\right)$ is an information system and $\mathbb{C}_{A T}=\left\{C_{a_{1}}, C_{a_{2}}, \cdots, C_{a_{m}}\right\}$ is a family of the coverings of $O B$ with respect to $A T$. For any $X \subseteq O B$,

$$
\begin{aligned}
& \underline{\operatorname{apr}}_{\mathbb{C}_{A T}}^{O}(X)=\cup\left\{x \in O B \mid\left(x \in K_{1}\left(\in C_{a_{1}}\right) \subseteq X\right) \vee\left(x \in K_{2}\left(\in C_{a_{2}}\right) \subseteq X\right) \vee \cdots \vee\left(x \in K_{m}\left(\in C_{a_{m}}\right) \subseteq X\right)\right\}, \\
& \overline{a p r}_{\mathbb{C}_{A T}}^{O}(X)=\sim \underline{a p r}_{\mathbb{C}_{A T}}^{O}(\sim X)
\end{aligned}
$$

are called the optimistic lower and upper approximations of $X$ with respect to the family of the coverings $\mathbb{C}_{A T}$.

Definition 2.11 Suppose that $I=\left(O B, A T,\left\{V_{a} \mid a \in A T\right\},\left\{f_{a} \mid a \in A T\right\}\right)$ is an information system and $\mathbb{C}_{A T}=\left\{C_{a_{1}}, C_{a_{2}}, \cdots, C_{a_{m}}\right\}$ is a family of the coverings of $O B$ with respect to $A T$. For any $X \subseteq O B$,

$$
\begin{aligned}
& \underline{\operatorname{apr}}^{P}(X)=\cup\left\{x \in O B \mid\left(x \in K_{1}\left(\in C_{a_{1}}\right) \subseteq X\right) \wedge\left(x \in K_{2}\left(\in C_{a_{2}}\right) \subseteq X\right) \wedge \cdots \wedge\left(x \in K_{m}\left(\in C_{a_{m}}\right) \subseteq X\right)\right\}, \\
& \overline{\operatorname{apr}}_{\mathbb{C}_{A T}}^{P}(X)=\sim \underline{\operatorname{apr}} \mathbb{C}_{\mathbb{A}^{\prime}}^{P}(\sim X)
\end{aligned}
$$

are called the pessimistic lower and upper approximations of $X$ with respect to the family of the coverings $\mathbb{C}_{A T}$.

\subsection{Reducts based on different granular structures}

Reduction is always a very important research content of granular computing theory. No matter what kind of granular computing model, its results of reduction theory are very rich. Here, we give the concepts of reduction for the four kinds of granular structures mentioned above. 
Definition 2.12 Suppose that $I=\left(O B, A T,\left\{V_{a} \mid a \in A T\right\},\left\{f_{a} \mid a \in A T\right\}\right)$ is an information system and $\mathcal{P}_{A T}$ is a partition of $O B$ with respect to $A T$. For any $a \in A T$, if $\mathcal{P}_{A T}=\mathcal{P}_{A T /\{a\}}$, we say that $a$ is a reducible attribute of $A T$ with respect to $\mathcal{P}_{A T}$, and $a$ is denoted by $a_{\text {reductp }}$; Otherwise, we say that $a$ is an irreducible attribute of $A T$ with respect to $\mathcal{P}_{A T}$. If $A T^{\prime} \subseteq A T$ meets two conditions: (1) for any $a \in A T / A T^{\prime}, a$ is the reducible attribute of $A T$ with respect to $\mathcal{P}_{A T}$; (2) for any $a \in A T^{\prime}, a$ is not the reducible attribute of $A T$ with respect to $\mathcal{P}_{A T}$. Then $A T^{\prime}$ is called the reduct of $A T$ with respect to $\mathcal{P}_{A T}$, and denoted by $\operatorname{reduct}(A T) \mathcal{P}_{A T}$.

Definition 2.13 Let $I=\left(O B, A T,\left\{V_{a} \mid a \in A T\right\},\left\{f_{a} \mid a \in A T\right\}\right)$ be an information system and $C_{A T}$ a covering of $O B$ with respect to $A T$. For $g \in C_{A T}$, if $g$ is the union (or intersection ) of some sets in $C /\{g\}$, we say that $g$ is the union (or intersection ) reducible element of $C_{A T}$, and $g$ is denoted by $(g)_{\text {reduct }_{C_{A T}, \cup}}$ ( or $(g)_{\text {reduct }_{\mathcal{C}_{A T}, \cap}}$ ); Otherwise, we say that $g$ is the union ( or intersection ) irreducible element of $C_{A T}$. If $C^{\prime} \subseteq C_{A T}$ meets two conditions: (1) for any $g \in C_{A T} / C^{\prime}$, $g$ is the union ( or intersection ) reducible element of $C_{A T}$; (2) for any $g \in C^{\prime}, g$ is not the union (or intersection ) reducible element of $C_{A T}$. Then $C^{\prime}$ is called the union ( or intersection ) reduct of $C_{A T}$, and denoted by $\operatorname{reduct}\left(C_{A T}\right) \cup$ $\left(\right.$ or $\left.\operatorname{reduct}\left(C_{A T}\right)_{\cap}\right)$.

Definition 2.14 Suppose $I=\left(O B, A T,\left\{V_{a} \mid a \in A T\right\},\left\{f_{a} \mid a \in A T\right\}\right)$ is an information system and $\mathbb{P}_{A T}=\left\{\mathcal{P}_{a_{1}}, \mathcal{P}_{a_{2}}, \cdots, \mathcal{P}_{a_{m}}\right\}$ is a family of the partitions of $O B$ with respect to $A T$. For any $a \in A T$ and any $P \in \mathcal{P}_{a}$, if there exist $\mathbb{P}_{A T}^{\prime} \subseteq \mathbb{P}_{A T} /\left\{\mathcal{P}_{a}\right\}$ and $\mathcal{P}^{\prime} \subseteq \widetilde{\mathcal{P}} \in \mathbb{P}_{A T}^{\prime}\left(\right.$ or $P^{\prime} \in \widetilde{\mathcal{P}} \in \mathbb{P}_{A T}^{\prime}$ ) such that $P=\cup_{\widetilde{\mathcal{P}}_{\in} \mathcal{P}_{A T}^{\prime}}\left(\cup \mathcal{P}^{\prime}\right)\left(\right.$ or $\left.P=\cap_{\widetilde{\mathcal{P}}_{\in} \mathbb{P}_{A T}^{\prime}} P^{\prime}\right)$, then $a$ is called the union (or intersection ) reducible attribute of $A T$ with respect to $\mathbb{P}_{A T}$, and $a$ is denoted by $a_{\text {reduct } \mathbb{P}_{A T}, \cup}$ ( or $a_{\text {reduct }}{\mathbb{\mathbb { P } _ { A T }}}_{\text {, }}$ ). Otherwise, $a$ is called the union ( or intersection ) irreducible attribute of $A T$ with respect to $\mathbb{P}_{A T}$. If $A T^{\prime} \subseteq A T$ meets two conditions: (1) for any $a \in A T / A T^{\prime}, a$ is the union ( or intersection ) reducible attribute of $A T$ with respect to $\mathbb{P}_{A T} ;(2)$ for any $a \in A T^{\prime}, a$ is not the union ( or intersection ) reducible attribute of $A T$ with respect to $\mathbb{P}_{A T}$. Then $A T^{\prime}$ is called the union ( or intersection ) reduct of $A T$ with respect to $\mathbb{P}_{A T}$, and denoted by $\operatorname{reduct}(A T)_{\mathbb{P}_{A T}, \cup}\left(\right.$ or $\left.\operatorname{reduct}(A T)_{\mathbb{P}_{A T}, \cap}\right)$.

\section{The granular structures induced by the binary information systems}

For an information system $I=\left(O B, A T,\left\{V_{a} \mid a \in A T\right\},\left\{f_{a} \mid a \in A T\right\}\right)$, where $A T=\left\{a_{1}, a_{2}, \cdots, a_{m}\right\}, I$ is called the binary information system or a $0-1$ information table, if for each $a \in A T, V_{a}=\{0,1\}$, where $f_{a}(x)=1$ means that $x$ has the attribute $a, f_{a}(x)=0$ means that $x$ does not have the attribute $a$. In this section, we mainly pay attention to the study of granular structures induced by the $0-1$ information table, and suppose that for each $x \in O B$, there exist $a, a^{\prime} \in A T$ such that $f_{a}(x)=1$ and $f_{a^{\prime}}(x)=0$.

In this section, we first introduce the induced elementary information granules and four kinds of granular structures induced by the $0-1$ information system, then explore the inclusion relationship among the rough set models developed from these granular structures, and finally compare the relationship among the reductions based on these four kinds of granular structures.

\subsection{Granules and granular structures induced by the binary information systems}

From the $0-1$ information table, the elementary granular structures first can be induced as follows:

$$
\mathcal{G}=\left\{g_{j}^{a_{i}}=\left\{x \in O B \mid f_{a_{i}}(x)=j\right\} \mid i=1,2, \cdots, m, j=0,1\right\}
$$

For any $a \in A T, g_{1}^{a}$ is the set of all objects with attribute $a$, and $g_{0}^{a}$ is the set of all objects without attribute $a$.

Based on the $0-1$ information table and the elementary granular structures, four kinds of special granular structures can be explored as follows:

(1) The partition of $O B$ with respect to $A T$ :

$$
\mathcal{P}_{A T}=\left\{g_{1}, g_{2}, \cdots, g_{s}\right\}
$$

where for any $x, y \in g \in \mathcal{P}_{A T}, f_{a_{i}}(x)=f_{a_{i}}(y), i=1,2, \cdots, m$. For any $g^{\prime}, g^{\prime \prime} \in \mathcal{P}_{A T}$, any $x \in g^{\prime}$ and any $y \in g^{\prime \prime}$, there exist $a \in A T$ such that $f_{a}(x) \neq f_{a}(y)$. And $\cup_{i=1}^{s} g_{i}=O B$.

(2) The covering of $O B$ with respect to $A T$ : 
$C_{A T}$ consists of all elementary information granules in the information system.

(3) The multi-partition of $O B$ with respect to $A T$ :

$$
\mathbb{P}_{A T}=\left\{\mathcal{P}_{a_{1}}, \mathcal{P}_{a_{2}}, \cdots, \mathcal{P}_{a_{m}}\right\}
$$

where $\mathcal{P}_{a_{i}}=\left\{g_{1}^{a_{i}}, g_{0}^{a_{i}}\right\}, i=1,2, \cdots, m$.

(4) The multi-covering of $O B$ with respect to $A T$ :

$$
\mathbb{C}_{A T}=\left\{C_{1}, C_{0}\right\}
$$

where $C_{1}=\left\{g_{1}^{a_{1}}, g_{1}^{a_{2}}, \cdots, g_{1}^{a_{m}}\right\}$, and $C_{0}=\left\{g_{0}^{a_{1}}, g_{0}^{a_{2}}, \cdots, g_{0}^{a_{4}}\right\}$.

Based on the above analysis, a binary information table can induce four kinds of granular structures. In the following, we give an example to explain the induced elementary information granules and granular structures in the binary information table.

Example 3.1 Here is a $0-1$ information table $I=\left(O B, A T,\left\{V_{a} \mid a \in A T\right\},\left\{f_{a} \mid a \in A T\right\}\right)$, where $O B=\left\{x_{1}, x_{2}, \cdots, x_{8}\right\}$, $A T=\left\{a_{1}, a_{2}, a_{3}, a_{4}\right\}$. More details can be shown in Table 1 as follows.

Table 1. A $0-1$ information table

\begin{tabular}{c|cccc}
\hline$O B$ & $a_{1}$ & $a_{2}$ & $a_{3}$ & $a_{4}$ \\
\hline$x_{1}$ & 1 & 1 & 0 & 0 \\
$x_{2}$ & 0 & 1 & 0 & 1 \\
$x_{3}$ & 0 & 0 & 1 & 1 \\
$x_{4}$ & 1 & 1 & 0 & 0 \\
$x_{5}$ & 0 & 1 & 0 & 1 \\
$x_{6}$ & 0 & 0 & 0 & 1 \\
$x_{7}$ & 1 & 0 & 0 & 1 \\
$x_{8}$ & 1 & 1 & 1 & 0 \\
\hline
\end{tabular}

Based on the Table 1, all of the elementary granules can be shown as follows:

$g_{1}^{a_{1}}=\left\{x_{1}, x_{4}, x_{7}, x_{8}\right\}, g_{0}^{a_{1}}=\left\{x_{2}, x_{3}, x_{5}, x_{6}\right\} ; g_{1}^{a_{2}}=\left\{x_{1}, x_{2}, x_{4}, x_{5}, x_{8}\right\}, g_{0}^{a_{2}}=\left\{x_{3}, x_{6}, x_{7}\right\} ; g_{1}^{a_{3}}=\left\{x_{3}, x_{8}\right\}, g_{0}^{a_{3}}=$ $\left\{x_{1}, x_{2}, x_{4}, x_{5}, x_{6}, x_{7}\right\} ; g_{1}^{a_{4}}=\left\{x_{2}, x_{3}, x_{5}, x_{6}, x_{7}\right\}, g_{0}^{a_{4}}=\left\{x_{1}, x_{4}, x_{8}\right\}$.

According to these elementary granules, four kinds of granular structures can be induced as follows:

(1) The partition of $O B$ with respect to $A T$ :

$\mathcal{P}_{A T}=\left\{\left\{x_{1}, x_{4}\right\},\left\{x_{2}, x_{5}\right\},\left\{x_{3}\right\},\left\{x_{6}\right\},\left\{x_{7}\right\},\left\{x_{8}\right\}\right\}$;

(2) The multi-partition of $O B$ with respect to $A T$ :

$\mathbb{P}_{A T}=\left\{\mathcal{P}_{a_{1}}, \mathcal{P}_{a_{2}}, \mathcal{P}_{a_{3}}, \mathcal{P}_{a_{4}}\right\}$

$=\left\{\left\{g_{1}^{a_{1}}, g_{0}^{a_{1}}\right\},\left\{g_{1}^{a_{2}}, g_{0}^{a_{2}}\right\},\left\{g_{1}^{a_{3}}, g_{0}^{a_{3}}\right\},\left\{g_{1}^{a_{4}}, g_{0}^{a_{4}}\right\}\right\}$

$=\left\{\left\{\left\{x_{1}, x_{4}, x_{7}, x_{8}\right\},\left\{x_{2}, x_{3}, x_{5}, x_{6}\right\}\right\},\left\{\left\{x_{1}, x_{2}, x_{4}, x_{5}, x_{8}\right\},\left\{x_{3}, x_{6}, x_{7}\right\}\right\},\left\{\left\{x_{3}, x_{8}\right\},\left\{x_{1}, x_{2}, x_{4}, x_{5}, x_{6}, x_{7}\right\}\right\}\right.$,

$\left.\left\{\left\{x_{2}, x_{3}, x_{5}, x_{6}, x_{7}\right\},\left\{x_{1}, x_{4}, x_{8}\right\}\right\}\right\}$;

(3) The covering of $O B$ with respect to $A T$ :

$C_{A T}=\left\{g_{1}^{a_{1}}, g_{0}^{a_{1}}, g_{1}^{a_{2}}, g_{0}^{a_{2}}, g_{1}^{a_{3}}, g_{0}^{a_{3}}, g_{1}^{a_{4}}, g_{0}^{a_{4}}\right\}$

$=\left\{\left\{x_{1}, x_{4}, x_{7}, x_{8}\right\},\left\{x_{2}, x_{3}, x_{5}, x_{6}\right\},\left\{x_{1}, x_{2}, x_{4}, x_{5}, x_{8}\right\},\left\{x_{3}, x_{6}, x_{7}\right\},\left\{x_{3}, x_{8}\right\},\left\{x_{1}, x_{2}, x_{4}, x_{5}, x_{6}, x_{7}\right\}\right.$,

$\left.\left\{x_{2}, x_{3}, x_{5}, x_{6}, x_{7}\right\},\left\{x_{1}, x_{4}, x_{8}\right\}\right\}$;

(4) The multi-covering of $O B$ with respect to $A T$ :

$\mathbb{C}_{A T}=\left\{C_{1}, C_{0}\right\}$

$=\left\{\left\{g_{1}^{a_{1}}, g_{1}^{a_{2}}, g_{1}^{a_{3}}, g_{1}^{a_{4}}\right\},\left\{g_{0}^{a_{1}}, g_{0}^{a_{2}}, g_{0}^{a_{3}}, g_{0}^{a_{4}}\right\}\right\}$

$=\left\{\left\{\left\{x_{1}, x_{4}, x_{7}, x_{8}\right\},\left\{x_{1}, x_{2}, x_{4}, x_{5}, x_{8}\right\},\left\{x_{3}, x_{8}\right\},\left\{x_{2}, x_{3}, x_{5}, x_{6}, x_{7}\right\}\right\},\left\{\left\{x_{2}, x_{3}, x_{5}, x_{6}\right\},\left\{x_{3}, x_{6}, x_{7}\right\}\right.\right.$,

$\left.\left.\left\{x_{1}, x_{2}, x_{4}, x_{5}, x_{6}, x_{7}\right\},\left\{x_{1}, x_{4}, x_{8}\right\}\right\}\right\}$. 


\subsection{The relationship among the rough set models induced by the binary information systems}

We know that four kinds of granular structures can be induced from a binary information table, and then four rough set models can be constructed according to these granular structures. In this subsection, we study the relationship among these rough set models.

Proposition 3.1 Suppose that $I=\left(O B, A T,\left\{V_{a} \mid a \in A T\right\},\left\{f_{a} \mid a \in A T\right\}\right)$ is a $0-1$ information system. For any $X \subseteq O B$, the following results hold.

(1) $\underline{a p r}_{\mathbb{C}_{A T}^{O}}^{O}(X)=\underline{\operatorname{apr}} \mathbb{P}_{A T}^{O}(X)=\underline{\operatorname{apr}}_{C_{A T}}(X) \subseteq \underline{\operatorname{apr}}_{\mathcal{P}_{A T}}(X)$

(2) $\overline{a p r}_{\mathcal{P}_{A T}}(X) \subseteq \overline{a p r}_{\mathbb{C}_{A T}}^{O}(X)=\overline{a p r}_{\mathbb{P}_{A T}}^{O}(X)=\overline{a p r}_{C_{A T}}(X)$

Proof. It is clear from the definitions of equations (1)-(4).

Example 3.2 (Continued from Example 3.1) For $X=\left\{x_{1}, x_{2}, x_{4}, x_{5}\right\}$, we have that $\underline{a p r}_{M C_{A T}}^{O}(X)=\underline{a p r}_{M P_{A T}}^{O}(X)=$ $\underline{\operatorname{apr}}_{C_{A T}}(X)=\emptyset, \underline{\operatorname{apr}}_{P_{A T}}(X)=\left\{x_{1}, x_{2}, x_{4}, x_{5}\right\}$. Then $\underline{\operatorname{apr}}_{\mathbb{C}_{A T}^{O}}(X)=\underline{\operatorname{apr}} \underline{\mathbb{P}}_{A T}^{O}(X)=\underline{\operatorname{apr}}_{C_{A T}}(X) \subseteq \underline{\operatorname{apr}} \underline{\mathcal{P}}_{A T}(X)$.

For $Y=\left\{x_{3}, x_{6}, x_{7}, x_{8}\right\}$, we have that $\overline{a p r}_{M C_{A T}}^{O}(Y)=\overline{a p r}_{M P_{A T}}^{O}(Y)=\overline{a p r}_{C_{A T}}(Y)=O B, \overline{a p r}_{P_{A T}}(Y)=\left\{x_{3}, x_{6}, x_{7}, x_{8}\right\}$. So $\overline{\operatorname{apr}}_{\mathcal{P}_{A T}}(X) \subseteq \overline{\operatorname{apr}}_{\mathbb{C}_{A T}}^{O}(X)=\overline{a p r}_{\mathbb{P}_{A T}}^{O}(X)=\overline{a p r}_{C_{A T}}(X)$.

What is the relationship between $\underline{\operatorname{apr}^{P}} \mathbb{P}_{A T}(X)$ and $\underline{\operatorname{apr}^{P}} \mathbb{C}_{A T}(X)\left(\overline{\operatorname{apr}}_{\mathbb{C}_{A T}}^{P}(X)\right.$ and $\left.\overline{\operatorname{apr}}_{\mathbb{P}_{A T}}^{P}(X)\right)$. Let's illustrate this problem with an example.

Example 3.3 On the one hand, suppose that $g_{1}^{a_{1}}=\left\{x_{1}, x_{2}, x_{3}\right\}, g_{0}^{a_{1}}=\left\{x_{4}, x_{5}, x_{6}, x_{7}, x_{8}\right\}, g_{1}^{a_{2}}=\left\{x_{4}, x_{5}, x_{6}, x_{7}, x_{8}\right\}, g_{0}^{a_{2}}=$ $\left\{x_{1}, x_{2}, x_{3}\right\}, g_{1}^{a_{3}}=\left\{x_{1}, x_{2}, x_{3}, x_{4}\right\}, g_{0}^{a_{3}}=\left\{x_{5}, x_{6}, x_{7}, x_{8}\right\}$ are the elementary information granules of an information system. For $X=\left\{x_{1}, x_{2}, x_{3}\right\}$, we have that $\underline{a p r}_{\mathbb{P}_{A T}}^{P}(X) \subseteq \operatorname{apr}_{\mathbb{C}_{A T}^{P}}^{P}(X)$ and $\overline{a p r}_{\mathbb{C}_{A T}}^{P}(X) \subseteq \overline{\operatorname{apr}}_{\mathbb{P}_{A T}}^{P}(X)$.

On the other hand, let $g_{1}^{a_{1}}=\left\{x_{1}, x_{2}, x_{3}\right\}, g_{0}^{a_{1}}=\left\{x_{4}, x_{5}\right\}, g_{1}^{a_{2}}=\left\{x_{1}, x_{2}, x_{3}\right\}, g_{0}^{a_{2}}=\left\{x_{4}, x_{5}\right\}$ be the elementary information granules of some information system. For $X=\left\{x_{3}, x_{4}, x_{5}\right\}$, we have that $\underline{a p r} \mathbb{C}_{A T}^{P}(X) \subseteq \underline{a^{p} r^{P}}(X)$ and $\overline{\operatorname{apr}}_{\mathbb{P}_{A T}}^{P}(X) \subseteq \overline{\operatorname{apr}}_{\mathbb{C}_{A T}}^{P}(X)$.

\subsection{The relationship among the reducts induced by the binary information systems}

Reduction is a hot issue in granular computing theory. Based on the binary information system, four kinds of granular structures can be induced. In this part, we first give the definitions of reductions on the corresponding granular structures, and then compare the relationship among the reductions.

Definition 3.1 Suppose that $I=\left(O B, A T,\left\{V_{a} \mid a \in A T\right\},\left\{f_{a} \mid a \in A T\right\}\right)$ is a $0-1$ information system, and $C_{A T}=$ $\left\{g_{1}^{a_{1}}, g_{0}^{a_{1}}, g_{1}^{a_{2}}, g_{0}^{a_{2}}, \cdots, g_{1}^{a_{m}}, g_{0}^{a_{m}}\right\}$ is a covering of $O B$ with respect to $A T$. For any $a \in A T$, there exist $C_{i} \subseteq C_{A T} /\left\{g_{1}^{a}, g_{0}^{a}\right\}$ such that $g_{i}^{a}=\cup_{g \in C_{i}} g$ ( or $g_{i}^{a}=\cap_{g \in C_{i}} g$ ), where $i=0,1$, then $a$ is called the union ( or intersection ) reducible attribute of $A T$ with respect to $C_{A T}$, and denoted by $a_{\text {reduct }}$ A $_{\mathcal{A}_{T}, \cup}$ ( or $a_{\text {reduct }_{\mathcal{C}_{A T}, \cup}}$ ). If $A T^{\prime} \subseteq A T$ meets two conditions: (1) for any $a \in A T / A T^{\prime}, a$ is the union ( or intersection ) reducible attribute of $A T$ with respect to $C_{A T}$; (2) for any $a \in A T^{\prime}$, $a$ is not the union ( or intersection ) reducible attribute of $A T$ with respect to $C_{A T}$. Then $A T^{\prime}$ is called the union ( or intersection ) reduct of $A T$ with respect to $C_{A T}$, and denoted by $\operatorname{reduct}(A T)_{\mathcal{C}_{A T}, \mathrm{U}}\left(\right.$ or $\left.\operatorname{reduct}(A T)_{\mathcal{C}_{A T}, \cap}\right)$.

Definition 3.2 Suppose that $I=\left(O B, A T,\left\{V_{a} \mid a \in A T\right\},\left\{f_{a} \mid a \in A T\right\}\right)$ is a $0-1$ information system and $\mathbb{C}_{A T}=\left\{C_{1}, C_{0}\right\}$ is a multi-covering of $O B$ with respect to $A T$. If $g_{j}^{a}$ is the union ( or intersection ) of some sets in $C_{j} /\left\{g_{j}^{a}\right\}$ (where $C_{j} \in \mathbb{C}_{A T}$ ), then $g_{j}^{a}$ is called the union ( or intersection ) reducible element of $\mathbb{C}_{A T}$ with respect to $C_{j}$, and is

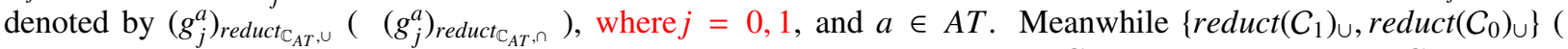
$\left\{\operatorname{reduct}\left(C_{1}\right)_{\cap}\right.$, reduct $\left.\left.\left(C_{0}\right)_{\cap}\right\}\right)$ is called the union ( or intersection ) reduct of $\mathbb{C}_{A T}$, denoted by $\operatorname{reduct}\left(\mathbb{C}_{A T}\right)_{\cup}($ or $\left.\operatorname{reduct}\left(\mathbb{C}_{A T}\right)_{\cap}\right)$.

Definition 3.3 Suppose that $I=\left(O B, A T,\left\{V_{a} \mid a \in A T\right\},\left\{f_{a} \mid a \in A T\right\}\right)$ is a $0-1$ information system and $\mathbb{C}_{A T}=\left\{C_{1}, C_{0}\right\}$ is a multi-covering of $O B$ with respect to $A T$. For any $a \in A T$, and any $g_{i}^{a} \in C_{i}$, there exist $C_{i}^{\prime} \subseteq C_{i} /\left\{g_{i}^{a}\right\}$ (where $C_{i} \in \mathbb{C}_{A T}$ ) such that $g_{i}^{a}=\cup_{g \in C_{i}^{\prime}} g$ ( or $g_{i}^{a}=\cap_{g \in C_{i}^{\prime}} g$ ), $i=0,1$, then $a$ is called the union ( or intersection ) reducible attribute of $A T$ with respect to $\mathbb{C}_{A T}$, and denoted by $a_{\text {reduct } \mathbb{C}_{A T}, \cup}$ ( or $a_{\text {reduct }}{\mathbb{\mathbb { C } _ { A T } , \cap}}$ ). If $A T^{\prime} \subseteq A T$ meets two conditions: (1) for any $a \in A T / A T^{\prime}, a$ is the union ( or intersection ) reducible attribute of $A T$ with respect to $\mathbb{C}_{A T}$; (2) for any 
$a \in A T^{\prime}, a$ is not the union ( or intersection ) reducible attribute of $A T$ with respect to $\mathbb{C}_{A T}$. Then $A T^{\prime}$ is called the union ( or intersection ) reduct of $A T$ with respect to $\mathbb{C}_{A T}$, denoted by $\operatorname{reduct}(A T)_{\mathbb{C}_{A T}, \cup}\left(\right.$ or $\left.\operatorname{reduct}(A T)_{\mathbb{C}_{A T}, \cap}\right)$.

Firstly, we study the influences of reductions among these rough set models, and find that different reductions have different effects on these rough set models. The detailed conclusions are presented as follows.

Proposition 3.2 Suppose that $I=\left(O B, A T,\left\{V_{a} \mid a \in A T\right\},\left\{f_{a} \mid a \in A T\right\}\right)$ is a $0-1$ information system. For any $X \subseteq O B$, the following results hold.
(1) $\underline{\operatorname{apr}}_{\operatorname{reduct}(A T)_{\mathcal{P}_{A T}}}(X)=\underline{\operatorname{apr}}_{\mathcal{P}_{A T}}(X), \overline{a p r}_{\text {reduct }(A T)_{\mathcal{P}_{A T}}}(X)=\overline{a p r}_{\mathcal{P}_{A T}}(X)$;
(2) $\underline{\operatorname{apr}}_{\operatorname{reduct}(A T)_{\mathcal{C}_{A T}, U}}(X)=\underline{\operatorname{apr}}_{C_{A T}}(X), \overline{\operatorname{apr}}_{\text {reduct }(A T)_{C_{A T}, U}}(X)=\overline{\operatorname{apr}}_{C_{A T}}(X)$;
(3) $\underline{\operatorname{apr}}_{\operatorname{reduct}\left(C_{A T}\right) \cup}(X)=\underline{\operatorname{apr}}_{C_{A T}}(X), \overline{\operatorname{apr}}_{\text {reduct }\left(C_{A T}\right) \cup}(X)=\overline{\operatorname{apr}}_{C_{A T}}(X)$;
(4) $\underline{\operatorname{apr}}_{\text {reduct }(A T)_{\mathbb{P}_{A T}, U}^{O}}^{O}(X)=\underline{\operatorname{apr}} \mathbb{P}_{\mathbb{P}_{A T}}^{O}(X), \overline{\operatorname{apr}}_{\text {reduct }(A T)_{\mathbb{P}_{A T}, \cup}^{O}}^{O}(X)=\overline{\operatorname{apr}}_{\mathbb{P}_{A T}}^{O}(X)$;
(5) $\underline{\operatorname{apr}}_{\text {reduct }(A T)_{\mathbb{P}_{A T}, U}^{P}}^{P}(X)=\underline{a p r}_{\mathbb{P}_{A T}^{P}}^{P}(X), \overline{\operatorname{apr}}_{\text {reduct }(A T)_{\mathbb{P}_{A T}, U}^{P}}^{P}(X)=\overline{\operatorname{apr}}_{\mathbb{P}_{A T}}^{P}(X)$;
(6) $\underline{\operatorname{apr}}_{\text {reduct }\left(\mathbb{C}_{A T}\right)_{\cup}}^{O}(X)=\underline{\operatorname{apr}}_{\mathbb{C}_{A T}^{O}}^{O}(X), \overline{\operatorname{apr}}_{\text {reduct }\left(\mathbb{C}_{A T}\right)_{\cup}}^{O}(X)=\overline{\operatorname{apr}}_{\mathbb{C}_{A T}}^{O}(X)$;
(7) $\underline{\operatorname{apr}}_{\operatorname{reduct}\left(\mathbb{C}_{A T}\right) \cup}^{P}(X)=\underline{\operatorname{apr}}{\mathbb{\mathbb { C } _ { A T }}}^{P}(X), \overline{\operatorname{apr}}_{\text {reduct }}^{P}\left(\mathbb{C}_{A T}\right) \cup(X)=\overline{\operatorname{apr}}_{\mathbb{C}_{A T}}^{P}(X)$;
(8) $\underline{\operatorname{apr}}_{\text {reduct }(A T)_{\mathbb{C}_{A T}, \cup}^{O}}^{O}(X)=\underline{\operatorname{apr}}_{\mathbb{C}_{A T}^{O}}^{O}(X), \overline{\operatorname{apr}}_{\text {reduct }(A T)_{\mathbb{C}_{A T}, \cup}^{O}}^{O}(X)=\overline{\operatorname{apr}}_{\mathbb{C}_{A T}}^{O}(X)$;
(9) $\underline{\operatorname{apr}}_{\text {reduct }(A T)_{\mathbb{C}_{A T}, \cup}^{P}}^{P}(X)=\underline{\operatorname{apr}}_{\mathbb{C}_{A T}^{P}}^{P}(X), \overline{\operatorname{apr}}_{\text {reduct }(A T)_{\mathbb{C}_{A T}, \cup}^{P}}^{P}(X)=\overline{\operatorname{apr}}_{\mathbb{C}_{A T}}^{P}(X)$.

Proof. It is clear from the definitions of reductions and approximation operators.

Proposition 3.3 Suppose that $I=\left(O B, A T,\left\{V_{a} \mid a \in A T\right\},\left\{f_{a} \mid a \in A T\right\}\right)$ is a $0-1$ information system. For any $X \subseteq O B$, the following results hold.
(1) $\underline{\operatorname{apr}}_{\operatorname{reduct}(A T)_{C_{A T}, \cap}}(X) \subseteq \underline{\operatorname{apr}}_{C_{A T}}(X), \overline{\operatorname{apr}}_{\text {reduct }(A T)_{C_{A T}, \cap}}(X) \supseteq \overline{a p r}_{C_{A T}}(X)$;
(2) $\underline{\operatorname{apr}}_{\operatorname{reduct}\left(C_{A T}\right)_{\cap}}(X) \subseteq \underline{\operatorname{apr}}_{C_{A T}}(X), \overline{\operatorname{apr}}_{\text {reduct }\left(C_{A T}\right)_{\cap}}(X) \supseteq \overline{\operatorname{apr}}_{C_{A T}}(X)$;

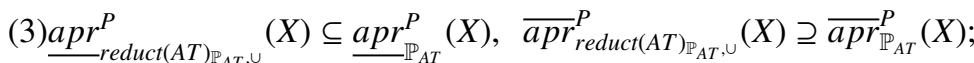

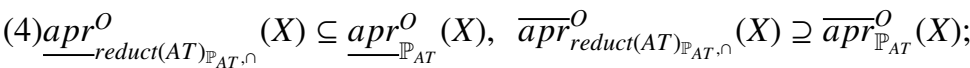
(5) $\underline{\operatorname{apr}}_{\text {reduct }(A T)_{\mathbb{P}_{A T}, \cap}^{P}}^{P}(X) \subseteq \underline{\operatorname{apr}} \underline{\mathbb{P}}_{\mathbb{A}^{P}}^{P}(X), \overline{\operatorname{apr}}_{\text {reduct }(A T)_{\mathbb{P}_{A T}, \cap}^{P}}^{P}(X) \supseteq \overline{\operatorname{apr}}_{\mathbb{P}_{A T}}^{P}(X)$;

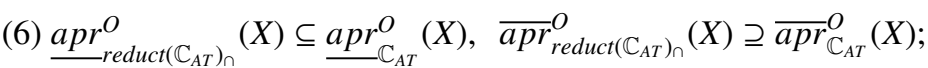
(7) $\underline{\operatorname{apr}}_{\text {reduct }\left(\mathbb{C}_{A T}\right)_{\cap}}^{P}(X) \subseteq \underline{\operatorname{apr}}{ }_{\mathbb{C}_{A T}^{P}}^{P}(X), \overline{\operatorname{apr}}_{\text {reduct }\left(\mathbb{C}_{A T}\right)_{\cap}}^{P}(X) \supseteq \overline{\operatorname{apr}}_{\mathbb{C}_{A T}^{P}}^{P}(X)$;

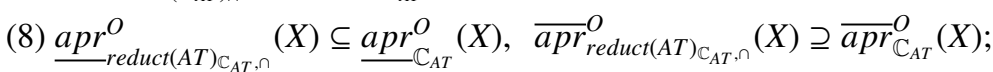
(9) $\underline{\operatorname{apr}}_{\text {reduct }(A T)_{\mathbb{C}_{A T}, \cap}^{P}}^{P}(X) \subseteq \underline{\operatorname{apr}}{\underline{\mathbb{C}_{A T}}}^{P}(X), \overline{\operatorname{apr}}_{\text {reduct }(A T)_{\mathbb{C}_{A T}, \cap}^{P}}^{P}(X) \supseteq \overline{\operatorname{apr}}_{\mathbb{C}_{A T}^{P}}^{P}(X)$.

Proof. It is clear from the definitions of reductions and approximation operators.

Based on the granular structure $C_{A T}$, the definitions of four kinds of reduction are proposed, from which four kinds of covering rough set models can be developed. Then the relationship among the approximation sets of these four kinds of rough set models is discussed.

Proposition 3.4 Suppose that $I=\left(O B, A T,\left\{V_{a} \mid a \in A T\right\},\left\{f_{a} \mid a \in A T\right\}\right)$ is a $0-1$ information system and $C_{A T}$ is a covering of $O B$ with respect to $A T$. For any $X \subseteq O B$, the following results hold.
(1) $\underline{a p r}_{\text {reduct }\left(C_{A T}\right.}$
$(X) \subseteq$ apr
$(X) \subseteq$ ap
$(X) \subseteq \underline{\operatorname{apr}}_{\operatorname{reduct}(A T)_{\mathcal{C}_{A T}, \cup}(X)}(X$
(2) $\overline{\operatorname{apr}}_{\text {reduct }(A T)_{\mathcal{C}_{A T}, \cup}}(X) \subseteq \overline{\operatorname{apr}}_{\text {reduct }\left(C_{A T}\right) \cup}(X) \subseteq \overline{\operatorname{apr}}_{\text {reduct }(A T)_{\mathcal{C}_{A T}, \cap}}(X) \subseteq \overline{\operatorname{apr}}_{\text {reduct }\left(C_{A T}\right)_{\cap}}(X)$. 


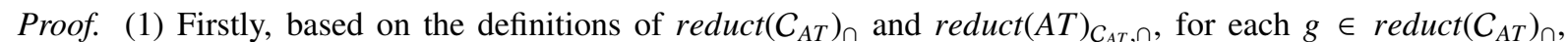
there exists $a \in \operatorname{reduct}(A T)_{\mathcal{C}_{A T}, \cap}$ such that $g=g_{1}^{a}$ or $g=g_{0}^{a}$. Then according to Definition 2.7, we have that

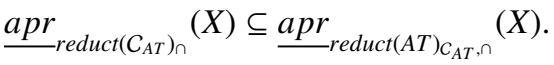

Secondly, since $\operatorname{reduct}\left(C_{A T}\right)_{\cup}$ is the union reduction of $C$, for each $X \subseteq O B$, equation $\underline{\operatorname{apr}}_{\operatorname{reduct}\left(C_{A T}\right)_{\cup}}(X)=$ $\underline{\operatorname{apr}}_{C_{A T}}(X)$ holds. And because $\operatorname{reduct}\left(C_{A T}\right) \cup$ is the intersection reduction of $C$, for each $X \subseteq O B$, one can find that $\underline{\text { apr }}_{\operatorname{reduct}\left(C_{A T}\right)_{\cap}}(X) \subseteq \underline{\operatorname{apr}}_{C_{A T}}(X)$ holds. So $\underline{\operatorname{apr}}_{\operatorname{reduct}\left(C_{A T}\right)_{\cap}}(X) \subseteq \underline{\operatorname{apr}}_{\operatorname{reduct}\left(C_{A T}\right) \cup}(X)$.

Finally, based on the definitions of $\operatorname{reduct}\left(C_{A T}\right)_{\cup}$ and $\operatorname{reduct}(A T)_{\mathcal{C}_{A T}, \cup}$, for each $g \in \operatorname{reduct}\left(C_{A T}\right)_{\cup}$, there exists $a \in \operatorname{reduct}(A T)_{\mathcal{C}_{A T}, \cup}$ such that $g=g_{1}^{a}$ or $g=g_{0}^{a}$. Then according to Definition 2.7, we have that $\underline{\text { apr }}$ reduct $\left(C_{A T)}(X) \subseteq\right.$ $\underline{\text { apr }}_{\text {reduct }(A T)_{C_{A T}, U}}(X)$.

(2) The proof of (2) is similar to that of (1).

According to the granular structure $\mathbb{P}_{A T}$, the definitions of four kinds of reduction are introduced, from which four kinds of multi-partition rough set models can be developed. Then the relationship among four kinds of rough set models is discussed.

Proposition 3.5 Suppose that $I=\left(O B, A T,\left\{V_{a} \mid a \in A T\right\},\left\{f_{a} \mid a \in A T\right\}\right)$ is a $0-1$ information system and $\mathbb{P}_{A T}$ is a multi-partition of $O B$ with respect to $A T$. For any $X \subseteq O B$, the following results hold.
(1) $\underline{\operatorname{apr}}_{\operatorname{reduct}(A T)_{\mathbb{P}_{A T}, \cap}^{P}}^{P}(X) \subseteq \underline{\operatorname{apr}}^{P} \operatorname{reduct(AT)\mathbb {P}_{AT},\cup }(X) \subseteq \underline{\operatorname{apr}}_{\operatorname{reduct}(A T)_{\mathbb{P}_{A T}, \cup}^{O}}(X) ;$

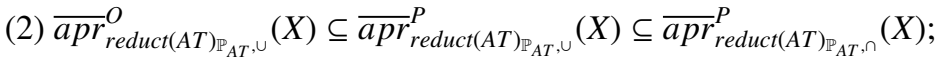
(3) $\underline{\operatorname{apr}}^{P} \operatorname{reduct(AT)_{\mathbb {P}_{AT},\cap }}(X) \subseteq \underline{\operatorname{apr}}_{\operatorname{reduct}(A T)_{\mathbb{P}_{A T}, \cap}^{O}}(X) \subseteq \underline{\operatorname{apr}}_{\operatorname{reduct}(A T)_{\mathbb{P}_{A T}, \cup}^{O}}(X)$;

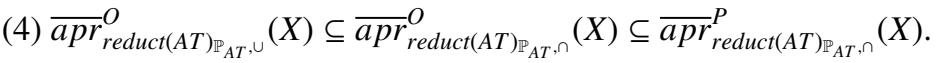

By the granular structure $\mathbb{C}_{A T}$, the definitions of two kinds of reductions are proposed, from which four kinds of multi-covering rough set models can be explored. Then the relationship among the approximation sets of these four kinds of rough set models is discussed.

Proposition 3.6 Suppose that $I=\left(O B, A T,\left\{V_{a} \mid a \in A T\right\},\left\{f_{a} \mid a \in A T\right\}\right)$ is a $0-1$ information system and $\mathbb{C}_{A T}$ is a multi-partition of $O B$ with respect to $A T$. For any $X \subseteq O B$, the following results hold.
(1) $\underline{\text { apr }}_{\text {reduct }\left(\mathbb{C}_{A T}\right)_{\cap}}^{P}(X) \subseteq \underline{\text { apr }}_{\text {reduct }(A T)_{\mathbb{C}_{A T}, \cap}^{P}}^{P}(X) \subseteq \underline{\operatorname{apr}}_{\operatorname{reduct}(A T)_{\mathbb{C}_{A T}, \cup}^{P}}^{P}(X)=\underline{\operatorname{apr}}_{\operatorname{reduct}\left(\mathbb{C}_{A T}\right)_{\cup}}^{P}(X) ;$

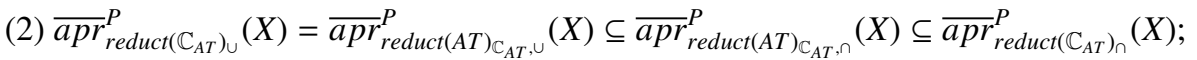

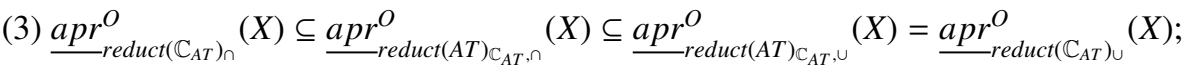

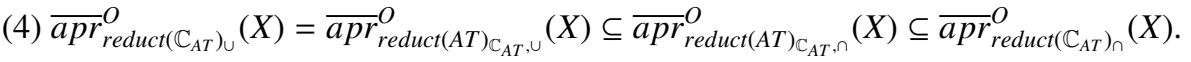

According to Example 3.1, we have $\mathcal{P}_{A T /\left\{a_{4}\right\}}=\mathcal{P}_{A T}$, i.e. $a_{4}$ is a reducible attribute of $A T$ with respect to $\mathcal{P}_{A T}$. Then, for any $X \subseteq O B, \underline{a p r}_{\mathcal{P}_{A T /\left\{a_{4}\right\}}}(X)=\underline{a p r}_{\mathcal{P}_{A T}}(X)$ and $\overline{a p r}_{\mathcal{P}_{\left.A T / a_{4}\right\}}}(X)=\overline{a p r}_{\mathcal{P}_{A T}}(X)$. So, for any $X \subseteq O B$, do the upper and lower approximation sets of $X$ shown from definitions 2.3-2.11 remain unchanged? The following example answers this question.

Example 3.4 (Continued from Example 3.1) According to Definitions 2.3-2.11, we have the following results.

(1) For $X=\left\{x_{1}, x_{2}, x_{4}, x_{8}\right\}$, we have that $\underline{a p r}_{C_{A T}}(X)=\left\{x_{1}, x_{4}, x_{8}\right\}, \underline{a p r}_{C_{A T /\left\{a_{4}\right\}}}(X)=\emptyset$, then $\underline{a p r}_{C_{A T /\left\{a_{4}\right\}}}(X) \neq \underline{a p r}_{C_{A T}}(X)$;

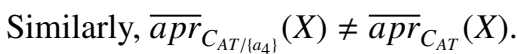

(2) For $X=\left\{x_{1}, x_{2}, x_{4}, x_{8}\right\}$, we have that $\underline{a p r} \underline{\mathbb{P}}_{A T}^{O}(X)=\left\{x_{1}, x_{4}, x_{8}\right\}, \underline{a p r} \underline{P}_{A T /\left\{a_{4}\right\}}^{O}(X)=\emptyset$, then $\underline{a p r} \mathbb{P}_{A T /\left\{a_{4}\right\}}^{O}(X) \neq \underline{a p r} \underline{P}_{\mathbb{P}_{A T}}^{O}(X)$; Similarly, $\overline{\operatorname{apr}}_{\mathbb{P}_{A T /\left\{a_{4}\right\}}}^{O}(X) \neq \overline{\operatorname{apr}}_{\mathbb{P}_{A T}}^{O}(X)$.

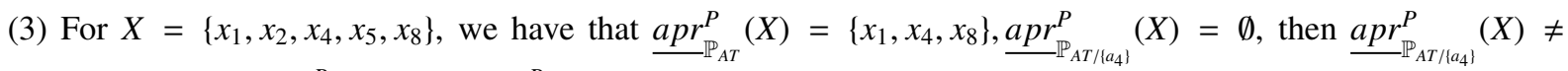
$\underline{\operatorname{apr}} \mathbb{P}_{A T}^{P}(X) ;$ Similarly, $\overline{\operatorname{apr}}_{\mathbb{P}_{A T /\left\{a_{4}\right\}}^{P}}^{P}(X) \neq \overline{\operatorname{apr}}_{\mathbb{P}_{A T}}^{P}(X)$. 
(4) For $X=\left\{x_{1}, x_{2}, x_{4}, x_{8}\right\}$, we have that $\underline{\operatorname{apr}} \mathbb{C}_{A T}^{O}(X)=\left\{x_{1}, x_{4}, x_{8}\right\}, \underline{a p r} \underline{\mathbb{C}}_{\left.A T / a_{4}\right\}}^{O}(X)=\emptyset$, then $\underline{\text { apr }} \underline{\mathbb{C}}_{A T /\left\{a_{4}\right\}}^{O}(X) \neq$

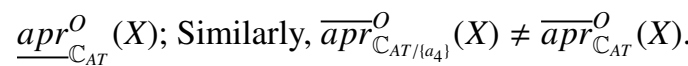

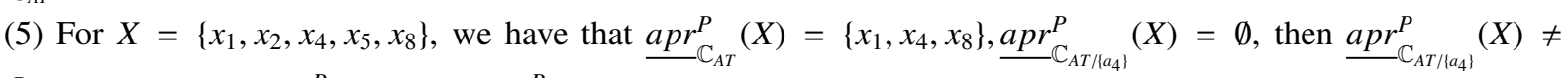
$\underline{\operatorname{apr}^{P}} \mathbb{C}_{A T}(X) ;$ Similarly, $\overline{\operatorname{apr}}_{\mathbb{C}_{A T /\left|a_{4}\right|}^{P}}(X) \neq \overline{\operatorname{apr}}_{\mathbb{C}_{A T}}^{P}(X)$.

Based on Example 3.4, for any $X \subseteq O B$, before and after attribute $a_{4}$ is deleted from Table 1, the lower and upper approximations of $X$ defined from Definitions 2.3-2.7 may be changed.

In the above, we mainly study the relationship of different reductions from the perspective of rough set model. Next, we will compare and study the relationship among the different reduction elements or reduction attributes.

Proposition 3.7 Suppose that $I=\left(O B, A T,\left\{V_{a} \mid a \in A T\right\},\left\{f_{a} \mid a \in A T\right\}\right)$ is a $0-1$ information system. If $a \in A T$ is a union ( or intersection ) reducible attribute of $A T$ with respect to $\mathbb{P}_{A T}$, then the following results hold.

(1) $a \in A T$ is a reducible attribute of $A T$ with respect to $\mathcal{P}_{A T}$;

(2) $a \in A T$ is a union ( or intersection ) reducible attribute of $A T$ with respect to $C_{A T}$;

(3) $g_{0}^{a}$ and $g_{1}^{a}$ are both the union ( or intersection ) reducible elements of $C_{A T}$.

Proof. Here, we prove the theorem only when $a$ is an union reducible attribute of $A T$ with respect to $\mathbb{P}_{A T}$. In the case that $a$ is an intersection reducible attribute of $A T$ with respect to $\mathbb{P}_{A T}$, the proof of the theorem is omitted.

(1) Let $\mathbb{P}_{A T}$ be the multi-partition of $O B$. For each $P \in \mathcal{P}_{a} \in \mathbb{P}_{A T}$, there exists $\mathcal{S} \subseteq \cup\left(\mathbb{P}_{A T} / \mathcal{P}_{a}\right)$ such that $P=\cup \mathcal{S}$. For each $x \in P$, there are a set family $\mathcal{P} \subseteq \mathcal{G}$ and a set $P^{\prime} \in \mathcal{P}_{A T}$ so that $x \in P^{\prime}=\cap \mathcal{P}$. Denote $\mathcal{S}_{x}=\{g \in \mathcal{S} \mid x \in g\}$, one can find that for each $g \in \mathcal{S}_{x}, g \subseteq P$. Since $a \in A T$ is a union reducible attribute of $A T$ with respect to $\mathbb{P}_{A T}$, so $\mathcal{S}_{x} \cup P \subseteq \mathcal{P}$. That is to say that $P^{\prime}=\cap \mathcal{P}=\cap \mathcal{S}_{x} \cap P \cap\left(\mathcal{P} /\left(\mathcal{S}_{x} \cup P\right)\right)=\cap \mathcal{S}_{x} \cap\left(\mathcal{P} /\left(\mathcal{S}_{x} \cup P\right)\right)=\cap(\mathcal{P} / P)$. Therefore, based on Definition 2.12, $a \in A T$ is a reducible attribute of $A T$ with respect to $\mathcal{P}_{A T}$.

(2) If $a \in A T$ is a union ( or intersection ) reducible attribute of $A T$ with respect to $\mathbb{P}_{A T}$, according to Definitions 2.12 and 2.13, it is easy to see that $a \in A T$ is a union ( or intersection ) reducible attribute of $A T$ with respect to $C_{A T}$.

(3) Based on Definitions 2.12 and 3.1, it is clear that the conclusion is true.

Proposition 3.8 Suppose that $I=\left(O B, A T,\left\{V_{a} \mid a \in A T\right\},\left\{f_{a} \mid a \in A T\right\}\right)$ is a $0-1$ information system. If $a \in A T$ is a union ( or intersection ) reducible attribute of $A T$ with respect to $\mathbb{P}_{A T}$ if and only if $a \in A T$ is a union (or intersection ) reducible attribute of $A T$ with respect to $C_{A T}$.

Proof. Based on the structure characteristics of $\mathbb{P}_{A T}, C_{A T}$, and Definitions 2.14 and 3.1 , it can be seen that the proposition is obviously correct.

Proposition 3.9 Suppose that $I=\left(O B, A T,\left\{V_{a} \mid a \in A T\right\},\left\{f_{a} \mid a \in A T\right\}\right)$ is a $0-1$ information system. If $a \in A T$ is a union ( or intersection ) reducible attribute of $A T$ with respect to $\mathbb{C}_{A T}$, then the following results hold.

(1) $a \in A T$ is a reducible attribute of $A T$ with respect to $\mathcal{P}_{A T}$;

(2) $a \in A T$ is a union ( or intersection ) reducible attribute of $A T$ with respect to $\mathbb{P}_{A T}$

(3) $a \in A T$ is a union ( or intersection ) reducible attribute of $A T$ with respect to $C_{A T}$;

(4) $g_{0}^{a}$ and $g_{1}^{a}$ are both the union ( or intersection ) reducible elements of $C_{A T}$;

(5) $g_{0}^{a}$ and $g_{1}^{a}$ are the union ( or intersection ) reducible elements of $\mathbb{C}_{A T}$ with respect to $C_{0}$ and $C_{1}$, respectively.

Proof. According to Proposition 3.7 and other relevant definitions, all conclusions are obvious.

Proposition 3.10 Suppose that $I=\left(O B, A T,\left\{V_{a} \mid a \in A T\right\},\left\{f_{a} \mid a \in A T\right\}\right)$ is a $0-1$ information system. If $g_{0}^{a}$ and $g_{1}^{a}$ are the union ( or intersection ) reducible elements of $\mathbb{C}_{A T}$ with respect to $C_{0}$ and $C_{1}$, respectively, the following results hold.

(1) $a$ is a union ( or intersection ) reducible attribute of $A T$ with respect to $\mathbb{C}_{A T}$;

(2) $a$ is a union ( or intersection ) reducible attribute of $A T$ with respect to $C_{A T}$;

(3) $g_{0}^{a}$ and $g_{1}^{a}$ are both the union ( or intersection ) reducible elements of $C_{A T}$.

Proof. Obviously, all the conclusions are true. 
Proposition 3.11 Suppose that $I=\left(O B, A T,\left\{V_{a} \mid a \in A T\right\},\left\{f_{a} \mid a \in A T\right\}\right)$ is a $0-1$ information system. If $a \in A T$ is a union reducible attribute of $A T$ with respect to $\mathbb{C}_{A T}$ if and only if $a \in A T$ is an intersection reducible attribute of $A T$ with respect to $\mathbb{C}_{A T}$.

Proof. Based on the structure characteristics of $\mathbb{C}_{A T}$ and Definition 3.3, it can be seen that the proposition is obviously true.

Through the discussion from Propositions 3.7-3.11, the relationship among all reductions is systematically discussed. In order to know the relationship among all reductions better, a relationship diagram among these reductions are shown as follows.

Figure 1. The relationship among the reducible attributes (or elements) in the $0-1$ information system

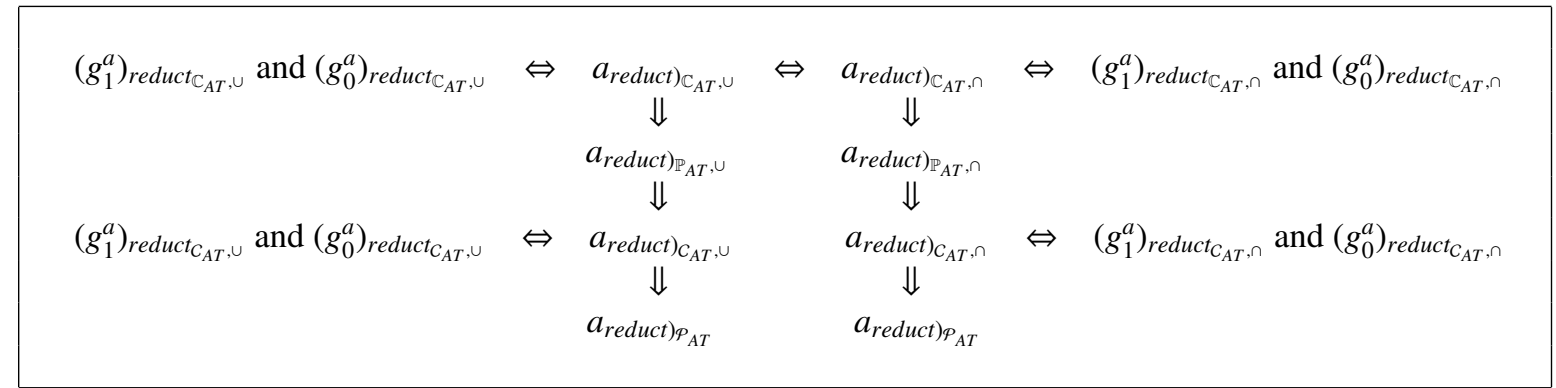

\section{The granular structures induced by the multi-valued information systems}

For an information system $I=\left(O B, A T,\left\{V_{a} \mid a \in A T\right\},\left\{f_{a} \mid a \in A T\right\}\right)$, where $A T=\left\{a_{1}, a_{2}, \cdots, a_{m}\right\}, I$ is called the multi-valued information system or the multi-valued information table, if for each $a_{i} \in A T, V_{a_{i}}=\left\{v_{a_{i}}, v_{a_{i} 2}, \cdots, v_{a_{i}} l_{i}\right\}, i=$ $1,2, \cdots, m$. In this section, we mainly pay attention to the study of elementary granules and granular structures induced by the multiple-valued information table.

In this part, we first study the induced elementary information granules and three kinds of granular structures coming from the multi-valued information system. Then we discuss the inclusion relationship among the rough set models obtained from these granular structures. Finally we will comparatively researched the relationship among the reductions according to these three kinds of granular structures.

\subsection{Granules and granular structures induced by the multi-valued information systems}

From the multi-valued information table, the elementary granular structures first can be induced as follows:

$$
\mathcal{G}=\left\{g_{v_{a_{i}}}^{a_{i}}=\left\{x \in O B \mid f_{a_{i}}(x)=v_{a_{i} j}\right\} \mid i=1,2, \cdots, m, j=1,2, \cdots, l_{i}\right\}
$$

In the last section, we know that four kinds of granular structures can be induced in binary information system. In the multi value information system, only three kinds of granular structures can be induced as follows.

(1) The partition of $O B$ with respect to $A T$ :

$$
\mathcal{P}_{A T}=\left\{g_{1}, g_{2}, \cdots, g_{s}\right\}
$$

where for any $x, y \in g_{i}, f_{a_{j}}(x)=f_{a_{j}}(y), i=1,2, \cdots, s ; j=1,2, \cdots, m$. For any $g, g^{\prime} \in \mathcal{P}_{A T}$ and for any $x \in g, x^{\prime} \in$ $g^{\prime}$, there exists $a \in A T$ such that $f_{a}(x) \neq f_{a}\left(x^{\prime}\right)$. And $\cup_{i=1}^{s} g_{i}=O B$.

(2) The covering of $O B$ with respect to $A T$ :

$$
C_{A T}=\left\{g_{v_{a_{i} j}}^{a_{i}} \mid i=1,2, \cdots, m, j=1,2, \cdots, l_{i}\right\}
$$

(3) The multi-partition of $O B$ with respect to $A T$ :

$$
\mathbb{P}_{A T}=\left\{\mathcal{P}_{1}, \mathcal{P}_{2}, \cdots, \mathcal{P}_{m}\right\}
$$


where $\mathcal{P}_{1}=\left\{g_{v_{a_{1}}}^{a_{1}}, g_{v_{a_{1} 2}}^{a_{1}}, \cdots, g_{v_{a_{1} l_{1}}}^{a_{1}}\right\}, \mathcal{P}_{2}=\left\{g_{v_{a_{2}}}^{a_{2}}, g_{v_{a_{2} 2}}^{a_{2}}, \cdots, g_{v_{a_{2} l_{2}}}^{a_{2}}\right\}, \cdots, \mathcal{P}_{m}=\left\{g_{v_{a_{1} 1}}^{a_{m}}, g_{v_{a_{m 2}}}^{a_{m}}, \cdots, g_{v_{a_{m} l_{m}}}^{a_{m}}\right\}$.

In the $0-1$ information table, we regard all information particles with attribute values of 0 as a covering, and all information particles with attribute values equal to $l$ as another covering. In this way, the two coverings are put together to obtain multiple coverings of $O B$. However, for a multi-valued information table, because attribute values are multi-valued, what rules are used to define multiple coverings? This question is difficult to answer.

Example 4.1 Here is a multi-valued information table $I=\left(O B, A T,\left\{V_{a} \mid a \in A T\right\},\left\{f_{a} \mid a \in A T\right\}\right)$, where $O B=$ $\left\{x_{1}, x_{2}, \cdots, x_{8}\right\}, A T=\left\{a_{1}, a_{2}, a_{3}, a_{4}\right\}$. More details can be shown in Table 2 as follows.

Table 2. A multi-valued information table

\begin{tabular}{c|cccc}
\hline$O B$ & $a_{1}$ & $a_{2}$ & $a_{3}$ & $a_{4}$ \\
\hline$x_{1}$ & 1 & 1 & 2 & 3 \\
$x_{2}$ & 2 & 3 & 1 & 1 \\
$x_{3}$ & 2 & 2 & 1 & 2 \\
$x_{4}$ & 3 & 1 & 2 & 3 \\
$x_{5}$ & 1 & 1 & 2 & 3 \\
$x_{6}$ & 3 & 1 & 2 & 3 \\
$x_{7}$ & 2 & 2 & 1 & 2 \\
$x_{8}$ & 1 & 4 & 1 & 3 \\
\hline
\end{tabular}

Clearly, all elementary granules induced by Table 2 can be shown as follows:

$g_{1}^{a_{1}}=\left\{x_{1}, x_{5}, x_{8}\right\}, g_{2}^{a_{1}}=\left\{x_{2}, x_{3}, x_{7}\right\}, g_{3}^{a_{1}}=\left\{x_{4}, x_{6}\right\} ; g_{1}^{a_{2}}=\left\{x_{1}, x_{4}, x_{5}, x_{6}\right\}, g_{2}^{a_{2}}=\left\{x_{3}, x_{7}\right\}, g_{3}^{a_{2}}=\left\{x_{2}\right\}, g_{4}^{a_{2}}=\left\{x_{8}\right\} ;$ $g_{1}^{a_{3}}=\left\{x_{2}, x_{3}, x_{7}, x_{8}\right\}, g_{2}^{a_{3}}=\left\{x_{1}, x_{4}, x_{5}, x_{6}\right\} ; g_{1}^{a_{4}}=\left\{x_{2}\right\}, g_{2}^{a_{4}}=\left\{x_{3}, x_{7}\right\}, g_{3}^{a_{4}}=\left\{x_{1}, x_{4}, x_{5}, x_{6}, x_{8}\right\}$.

According to these elementary granules, several special granular structures can be induced as follows:

(1) The partition of $O B$ with respect to $A T$ :

$\mathcal{P}_{A T}=\left\{\left\{x_{1}, x_{5}\right\},\left\{x_{2}\right\},\left\{x_{3}, x_{7}\right\},\left\{x_{4}, x_{6}\right\},\left\{x_{8}\right\}\right\} ;$

(2) The granular structure based on a covering of $O B$ with respect to $A T$ :

$C_{A T}=\left\{g_{1}^{a_{1}}, g_{2}^{a_{1}}, g_{3}^{a_{1}}, g_{1}^{a_{2}}, g_{2}^{a_{2}}, g_{3}^{a_{2}}, g_{4}^{a_{2}}, g_{1}^{a_{3}}, g_{2}^{a_{3}}, g_{1}^{a_{4}}, g_{2}^{a_{4}}, g_{3}^{a_{4}}\right\}$

$=\left\{\left\{x_{1}, x_{5}, x_{8}\right\},\left\{x_{2}, x_{3}, x_{7}\right\},\left\{x_{4}, x_{6}\right\},\left\{x_{1}, x_{4}, x_{5}, x_{6}\right\},\left\{x_{3}, x_{7}\right\},\left\{x_{2}\right\},\left\{x_{8}\right\},\left\{x_{2}, x_{3}, x_{7}, x_{8}\right\},\left\{x_{1}, x_{4}, x_{5}, x_{6}, x_{8}\right\}\right\}$;

(3) The multi-partitions of $O B$ with respect to $A T$ :

$\mathbb{P}_{A T}=\left\{\mathcal{P}_{a_{1}}, \mathcal{P}_{a_{2}}, \mathcal{P}_{a_{3}}, \mathcal{P}_{a_{4}}\right\}$

$=\left\{\left\{g_{1}^{a_{1}}, g_{2}^{a_{1}}, g_{3}^{a_{1}}\right\},\left\{g_{1}^{a_{2}}, g_{2}^{a_{2}}, g_{3}^{a_{2}}, g_{4}^{a_{2}}\right\},\left\{g_{1}^{a_{3}}, g_{2}^{a_{3}}\right\},\left\{g_{1}^{a_{4}}, g_{2}^{a_{4}}, g_{3}^{a_{4}}\right\}\right\}$

$=\left\{\left\{\left\{x_{1}, x_{5}, x_{8}\right\},\left\{x_{2}, x_{3}, x_{7}\right\},\left\{x_{4}, x_{6}\right\}\right\},\left\{\left\{x_{1}, x_{4}, x_{5}, x_{6}\right\},\left\{x_{3}, x_{7}\right\},\left\{x_{2}\right\},\left\{x_{8}\right\}\right\},\left\{\left\{x_{2}, x_{3}, x_{7}, x_{8}\right\},\left\{x_{1}, x_{4}, x_{5}, x_{6}\right\}\right\}\right.$,

$\left\{\left\{x_{2}\right\},\left\{x_{2}, x_{3}, x_{7}\right\},\left\{x_{1}, x_{4}, x_{5}, x_{6}, x_{8}\right\}\right\}$;

\subsection{The relationship among the rough set models induced by the multi-valued information systems}

Three kinds of granular structures can be obtained from the multi-valued information system. Similarly, three kinds of rough set models can be constructed naturally from these three kinds of granular structures. Next, the relationship of the upper and lower approximation sets in these three rough set models is discussed.

Proposition 4.1 Suppose that $I=\left(O B, A T,\left\{V_{a} \mid a \in A T\right\},\left\{f_{a} \mid a \in A T\right\}\right)$ is a multi-valued information system. For any $X \subseteq O B$, the following results hold.

(1) $\operatorname{apr}_{\mathbb{P}_{A T}^{P}}^{P}(X) \subseteq \underline{\operatorname{apr}}_{\mathbb{P}_{A T}^{O}}^{O}(X)=\underline{\operatorname{apr}}_{C_{A T}}(X) \subseteq \underline{\operatorname{apr}}_{\mathcal{P}_{A T}}(X)$;

(2) $\overline{\operatorname{apr}}_{\mathcal{P}_{A T}}(X) \subseteq \overline{a p r}_{\mathbb{P}_{A T}}^{O}(X)=\overline{a p r}_{C_{A T}}(X) \subseteq \overline{\operatorname{apr}}_{\mathbb{P}_{A T}}^{P}(X)$.

Proof. It can be easily proved based on the definitions of equations (5)-(7).

For any $X \subseteq O B$, there is no explicit inclusion relationship among the pessimistic lower and upper approximations of $X$, which are listed in Definitions 2.5 and 2.7. Let's illustrate this problem with an example. 
Example 4.2 (Continued from Example 4.1) For $X=\left\{x_{1}, x_{2}, x_{5}, x_{6}\right\}$, we have that $\underline{a p r} \underline{\mathbb{P}}_{A T}^{P}(X)=\emptyset, \underline{a p r} \underline{\mathbb{P}}_{A T}^{O}(X)=$ $\underline{\operatorname{apr}}_{C_{A T}}(X)=\left\{x_{2}\right\}, \underline{\operatorname{apr}}_{\mathcal{P}_{A T}}(X)=\left\{x_{1}, x_{2}, x_{5}\right\}$. Then $\underline{\operatorname{apr}} \mathbb{P}_{A T}^{P}(X) \subseteq \underline{\operatorname{apr}}_{\mathbb{P}_{A T}^{O}}^{O}(X)=\underline{\operatorname{apr}}_{C_{A T}}(X) \subseteq \underline{\operatorname{apr}} \underline{\mathcal{P}}_{A T}(X)$.

For $Y=\left\{x_{3}, x_{4}, x_{7}, x_{8}\right\}$, we have that $\overline{\operatorname{apr}}_{\mathcal{P}_{A T}}(Y)=\left\{x_{3}, x_{4}, x_{6}, x_{7}, x_{8}\right\}, \overline{a p r}_{\mathbb{P}_{A T}}^{O}(Y)=\overline{a p r}_{C_{A T}}(Y)=\left\{x_{1}, x_{3}, x_{4}, x_{5}, x_{6}, x_{7}\right.$, $\left.x_{8}\right\}, \underline{a p r}_{\mathbb{P}_{A T}^{P}}^{P}(X)=O B$. So $\overline{a p r}_{\mathcal{P}_{A T}}(X) \subseteq \overline{a p r}_{\mathbb{P}_{A T}}^{O}(X)=\overline{a p r}_{C_{A T}}(X) \subseteq \overline{a p r}_{\mathbb{P}_{A T}}^{P}(X)$.

\subsection{The relationship among the reductions induced by the multi-valued information systems}

Based on the multi-valued information system, three kinds of granular structures can be induced. In this part, we first add a concept of attribute reduction based on covering granular structure, and then comparatively study the relationship among the reductions based on these granular structures.

Definition 4.1 Suppose that $I=\left(O B, A T,\left\{V_{a} \mid a \in A T\right\},\left\{f_{a} \mid a \in A T\right\}\right)$ is a multi-valued information system, and $C_{A T}=\left\{g_{v_{a_{j}} j}^{a_{a}} \mid i=1,2, \cdots, m, j=1,2, \cdots, l_{i}\right\}$ is a covering of $O B$ with respect to $A T$. For any $a \in A T$, any $v_{a} \in V_{a}$, and any $g_{v_{a j}}^{a}, j \in\left\{1,2, \cdots, l_{i}\right\}$, there exist $C_{v_{a j}} \subseteq \mathcal{C}_{A T} / \mathcal{P}_{a}$ (where $\left.\mathcal{P}_{a} \in \mathbb{P}_{A T}\right)$ such that $g_{v_{a j}}^{a}=\cup_{g \in \mathcal{C}_{v_{j} j}} g\left(\right.$ or $g_{v_{a} j}^{a}=\cap_{g \in \mathcal{C}_{v_{a j}}} g$ ), then $a$ is called the union ( or intersection ) reducible attribute of $A T$ with respect to $C_{A T}$, and denoted by $a_{\text {reduct }}$ a $_{C_{A}, \cup}$ ( or $a_{\text {reduct }}$ C $_{A T}, \cup$ ). If $A T^{\prime} \subseteq A T$ meets two conditions: (1) for any $a \in A T / A T^{\prime}, a$ is the union (or intersection ) reducible attribute of $A T$ with respect to $C_{A T}$; (2) for any $a \in A T^{\prime}, a$ is not the union ( or intersection ) reducible attribute of $A T$ with respect to $C_{A T}$. Then $A T^{\prime}$ is called the union ( or intersection ) reduct of $A T$ with respect to $C_{A T}$, and denoted by $\operatorname{reduct}(A T)_{C_{A T}, \cup}\left(\right.$ or $\left.\operatorname{reduct}(A T)_{C_{A T}, \cap}\right)$.

The following results focus on the inclusion relations of the upper and lower approximation sets of different rough set models developed from equations (5)-(7).

Proposition 4.2 Suppose that $I=\left(O B, A T,\left\{V_{a} \mid a \in A T\right\},\left\{f_{a} \mid a \in A T\right\}\right)$ is a multi-valued information system. For any $X \subseteq O B$, the following results hold.
(1) $\underline{\operatorname{apr}}_{\operatorname{reduct}(A T)_{\mathcal{P}_{A T}}}(X)=\underline{\operatorname{apr}}_{\mathcal{P}_{A T}}(X), \overline{\operatorname{apr}}_{\text {reduct }(A T) \mathcal{P}_{A T}}(X)=\overline{\operatorname{apr}}_{\mathcal{P}_{A T}}(X)$;
(2) $\underline{\operatorname{apr}}_{\operatorname{reduct}(A T)_{\mathcal{C}_{A T}, \cup}}(X)=\underline{\operatorname{apr}}_{C_{A T}}(X), \overline{\operatorname{apr}}_{\operatorname{reduct}(A T)_{\mathcal{C}_{A T}, U}}(X)=\overline{\operatorname{apr}}_{C_{A T}}(X)$;
(3) $\underline{\operatorname{apr}}_{\operatorname{reduct}\left(C_{A T}\right) \cup}(X)=\underline{\operatorname{apr}}_{C_{A T}}(X), \overline{\operatorname{apr}}_{\text {reduct }\left(C_{A T}\right) \cup}(X)=\overline{\operatorname{apr}}_{C_{A T}}(X)$;
(4) $\underline{\operatorname{apr}}_{\operatorname{reduct}(A T)_{\mathbb{P}_{A T}, U}^{O}}^{O}(X)=\underline{\operatorname{apr}} \underline{\mathbb{P}}_{A T}^{O}(X), \overline{\operatorname{apr}}_{\text {reduct }(A T)_{\mathbb{P}_{A T}, U}^{O}}^{O}(X)=\overline{\operatorname{apr}}_{\mathbb{P}_{A T}}^{O}(X)$;
(5) $\underline{\operatorname{apr}}_{\text {reduct }(A T)_{\mathbb{P}_{A T}, \cap}^{P}}^{P}(X)=\underline{a p r}_{\mathbb{P}_{A T}^{P}}^{P}(X), \overline{\operatorname{apr}}_{\text {reduct }(A T)_{\mathbb{P}_{A T}, \cap}^{P}}^{P}(X)=\overline{\operatorname{apr}}_{\mathbb{P}_{A T}}^{P}(X)$;

Proposition 4.3 Suppose that $I=\left(O B, A T,\left\{V_{a} \mid a \in A T\right\},\left\{f_{a} \mid a \in A T\right\}\right)$ is a multi-valued information system. For any $X \subseteq O B$, the following results hold.

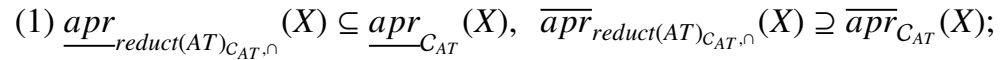
(2) $\underline{\operatorname{apr}}_{\operatorname{reduct}\left(C_{A T}\right)_{\cap}}(X) \subseteq \underline{\operatorname{apr}}_{C_{A T}}(X), \overline{\operatorname{apr}}_{\text {reduct }\left(C_{A T}\right)_{\cap}}(X) \supseteq \overline{\operatorname{apr}}_{C_{A T}}(X)$;
(3) $\underline{\operatorname{apr}}_{\text {reduct(AT) }}^{P}(X) \subseteq \underline{\operatorname{apr}} \underline{\mathbb{P}}_{\mathbb{P}_{A T}, U}^{P}(X), \overline{\operatorname{apr}}_{\text {reduct }(A T)_{\mathbb{P}_{A T}, U}}^{P}(X) \supseteq \overline{\operatorname{apr}}_{\mathbb{P}_{A T}}^{P}(X)$;
(4) $\underline{\operatorname{apr}}_{\text {reduct(AT) }}^{O}(X) \subseteq \underline{\operatorname{apr}} \underline{\mathbb{P}}_{\mathbb{P}_{A T}, \cap}^{O}(X), \overline{\operatorname{apr}}_{\text {reduct }(A T)_{\mathbb{P}_{A T}, \cap}^{O}}^{O}(X) \supseteq \overline{\operatorname{apr}}_{\mathbb{P}_{A T}}^{O}(X)$;
(5) $\underline{\operatorname{apr}}_{\text {reduct }(A T)_{\mathbb{P}_{A T}, \cap}^{P}}^{P}(X) \subseteq \underline{\operatorname{apr}} \mathbb{P}_{\mathbb{A}^{P}}^{P}(X), \overline{\operatorname{apr}}_{\text {reduct }(A T)_{\mathbb{P}_{A T}, \cap}^{P}}^{P}(X) \supseteq \overline{\operatorname{apr}}_{\mathbb{P}_{A T}}^{P}(X)$;

Proposition 4.4 Suppose that $I=\left(O B, A T,\left\{V_{a} \mid a \in A T\right\},\left\{f_{a} \mid a \in A T\right\}\right)$ is a multi-valued information system and $C_{A T}$ is a covering of $O B$ with respect to $A T$. For any $X \subseteq O B$, the following results hold.
(1) $\underline{a p r}_{\operatorname{reduct}\left(C_{A T}\right.}$
$(X) \subseteq \underline{a p r}$

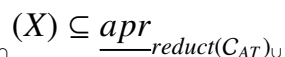
$(X) \subseteq \underline{\text { apr }}$
$(X)$
(2) $\overline{\operatorname{apr}}_{\text {reduct }(A T)_{\mathcal{C}_{A T}, \cup}}(X) \subseteq \overline{\operatorname{apr}}_{\text {reduct }\left(C_{A T}\right) \cup}(X) \subseteq \overline{a p r}_{\text {reduct }(A T)_{C_{A T}, \cap}}(X) \subseteq \overline{a p r}_{\text {reduct }\left(C_{A T}\right)_{\cap}}(X)$.

Proposition 4.5 Suppose that $I=\left(O B, A T,\left\{V_{a} \mid a \in A T\right\},\left\{f_{a} \mid a \in A T\right\}\right)$ is a multi-valued information system and $\mathbb{P}_{A T}$ is a multi-partition of $O B$ with respect to $A T$. For any $X \subseteq O B$, the following results hold.
(1) $\underline{\operatorname{apr}}_{\operatorname{reduct}(A T)_{\mathbb{P}_{A T}, \mathrm{~N}}^{P}}$
$(X) \subseteq \underline{\operatorname{apr}}_{r}^{P} \operatorname{reduct}(A T)_{\mathbb{P}_{A T},}$
$(X) \subseteq \underline{a p r}_{r e d u c t}^{O}$ $(X)$; 
(2) $\overline{\operatorname{apr}}_{\text {reduct }(A T)_{\mathbb{P}_{A T}, \cup}^{O}}^{O}(X) \subseteq \overline{\operatorname{apr}}_{\text {reduct }(A T)_{\mathbb{P}_{A T}, U}}^{P}(X) \subseteq \overline{\operatorname{apr}}_{\text {reduct }(A T)_{\mathbb{P}_{A T}, \cap}}^{P}(X)$;

(3) $\underline{\operatorname{apr}}_{r}^{P} \operatorname{reduct(AT)_{\mathbb {P}_{AT},\cap }}(X) \subseteq \underline{\operatorname{apr}}_{\operatorname{reduct}(A T)_{\mathbb{P}_{A T}, \cap}^{O}}(X) \subseteq \underline{\operatorname{apr}}_{\operatorname{reduct}(A T)_{\mathbb{P}_{A T}, \cup}^{O}}(X)$;

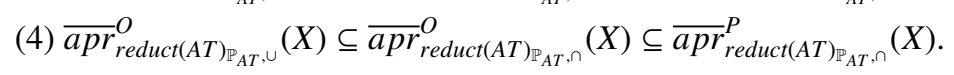

The following two propositions show the relationship among the attribute reductions of different granular structures from equations (5)-(7).

Proposition 4.6 Suppose that $I=\left(O B, A T,\left\{V_{a} \mid a \in A T\right\},\left\{f_{a} \mid a \in A T\right\}\right)$ is a multi-valued information system. If $a \in A T$ is a union (intersection) reducible attribute of $A T$ with respect to $\mathbb{P}_{A T}$, then the following results hold.

(1) $a \in A T$ is a reducible attribute of $A T$ with respect to $\mathcal{P}_{A T}$;

(2) $a \in A T$ is a union (intersection) reducible attribute of $A T$ with respect to $C_{A T}$;

(3) $g_{0}^{a}$ and $g_{1}^{a}$ are both the union (intersection) reducible elements of $C_{A T}$.

Proposition 4.7 Suppose that $I=\left(O B, A T,\left\{V_{a} \mid a \in A T\right\},\left\{f_{a} \mid a \in A T\right\}\right)$ is a multi-valued information system. If $a \in A T$ is a union (intersection) reducible attribute of $A T$ with respect to $\mathbb{P}_{A T}$ if and only if $a \in A T$ is a union (intersection) reducible attribute of $A T$ with respect to $C_{A T}$.

Figure 2. The relationship among the reducible attributes (or elements) in the multi-valued information system

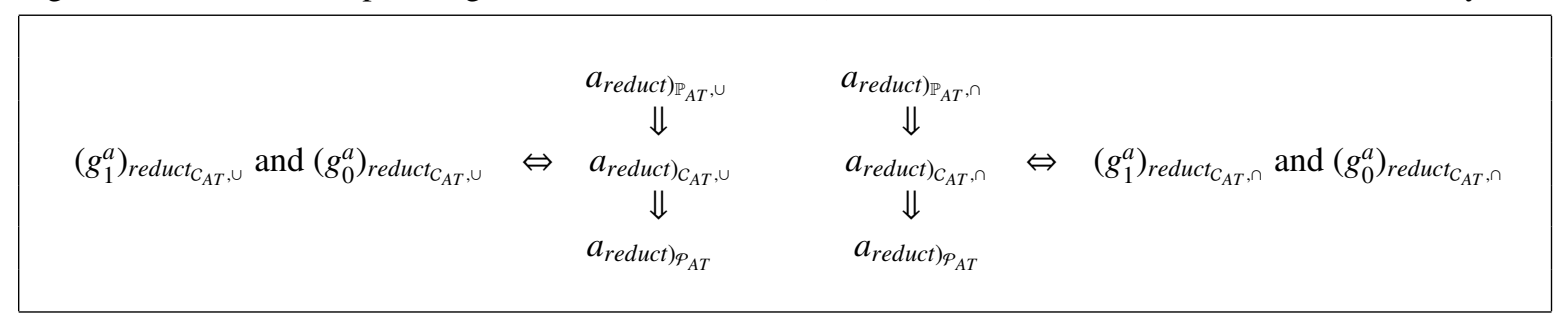

\section{The granular structures induced by set-valued information systems}

For an information system $I=\left(O B, A T,\left\{V_{a} \mid a \in A T\right\},\left\{f_{a} \mid a \in A T\right\}\right)$, where $A T=\left\{a_{1}, a_{2}, \cdots, a_{m}\right\}, I$ is called the set-valued information system or the set-valued information table, if for each $a_{i} \in A T, V_{a_{i}}=\left\{v_{a_{i} 1}, v_{a_{i} 2}, \cdots, v_{a_{i} l_{i}}\right\}$, and for each $x \in O B, f_{a_{i}}(x) \subseteq V_{a_{i}}, i=1,2, \cdots, m$. In this section, we mainly pay attention to the study of elementary granules and granular structures induced by the set-valued information table.

In this section, we first study the induced elementary information granules and four kinds of granular structures based on the set-valued information system, then research the inclusion relationship among the rough set models developed by these granular structures, and further discuss the relationship among the reductions based on these four kinds of granular structures.

\subsection{Granules and granular structures induced by the set-valued information systems}

From the set-valued information table, the elementary granular structures first can be induced as follows:

$$
\mathcal{G}=\left\{g_{v_{a_{i} j}}^{a_{i}}=\left\{x \in O B \mid v_{a_{i} j} \in f_{a_{i}}(x)\right\} \mid i=1,2, \cdots, m, j=1,2, \cdots, l_{i}\right\}
$$

Similar to the induced granular structures in the multi-valued information systems, four types of granular structures can be induced in the set-valued information systems as follows.

(1) The partition of $O B$ with respect to $A T$ :

$$
\mathcal{P}_{A T}=\left\{g_{1}, g_{2}, \cdots, g_{s}\right\}
$$

where for any $x, y \in g_{j}, f_{a_{i}}(x)=f_{a_{i}}(y), j=1,2, \cdots, s ; i=1,2, \cdots, m$. For any $g, g^{\prime} \in \mathcal{P}_{A T}$ and for any $x \in g, x^{\prime} \in$ $g^{\prime}$, there exists $a \in A T$ such that $f_{a}(x) \neq f_{a}\left(x^{\prime}\right)$. And $\cup_{i=1}^{s} g_{i}=O B$.

(2) The multi-partition of $O B$ with respect to $A T$ : 
where for any $P \in \mathcal{P}_{a_{i}}$ and any $x, y \in P, f_{a_{i}}(x)=f_{a_{i}}(y)$. And for any $P, P^{\prime} \in \mathcal{P}_{a_{i}}$ and any $x \in P, x^{\prime} \in P^{\prime}$, one can find that $f_{a_{i}}(x) \neq f_{a_{i}}\left(x^{\prime}\right), i=1,2, \cdots, m$.

(3) The multi-covering of $O B$ with respect to $A T$ :

$$
\mathbb{C}_{A T}=\left\{C_{a_{1}}, C_{a_{2}}, \cdots, C_{a_{m}}\right\}
$$

where $C_{a_{i}}=P_{a_{i}} \cup C_{a_{i}}^{\prime}$ and $C_{a_{i}}^{\prime}$ needs to meet two conditions: (1) For each $K \in C_{a_{i}}^{\prime}$, there exists $v_{a_{i} j} \in V_{a_{i}}$ such that $v_{a_{i} j} \in \cap_{x \in K} f_{a_{i}}(x)$; (2) For each $y \in O B / K, f_{a_{i}}(y) \cap\left(\cap_{x \in K} f_{a_{i}}(x)\right) \neq \cap_{x \in K} f_{a_{i}}(x)$, where $i=1,2, \cdots, m ; j=1,2, \cdots, l_{i}$.

(4) The covering of $O B$ with respect to $A T$

$$
C_{A T}=\left\{K_{1}, K_{2}, \cdots, K_{t}\right\}
$$

where any $K \in C_{A T}$ needs to meet two conditions: (1) $K \neq \emptyset$; (2) There are $K_{i}^{\prime} \in C_{a_{i}} \in \mathbb{C}_{A T}, i=1,2 . \cdots, m$ so that $K=K_{1}^{\prime} \cap K_{2}^{\prime} \cap \cdots \cap K_{m}^{\prime}$.

In order to better understand the elementary information granules and granular structures obtained from set-valued information systems, we will use the following examples to illustrate them.

Example 5.1 Here is a set-valued information table $I=\left(O B, A T,\left\{V_{a} \mid a \in A T\right\},\left\{f_{a} \mid a \in A T\right\}\right)$, where $O B=\left\{x_{1}, x_{2}, \cdots, x_{8}\right\}$, $A T=\left\{a_{1}, a_{2}, a_{3}, a_{4}\right\}$. More details can be shown in Table 3 as follows.

Table 3. A set-valued information table

\begin{tabular}{c|cccc}
\hline$O B$ & $a_{1}$ & $a_{2}$ & $a_{3}$ & $a_{4}$ \\
\hline$x_{1}$ & $\{1\}$ & $\{2\}$ & $\{1,3\}$ & $\{1\}$ \\
$x_{2}$ & $\{2\}$ & $\{1,2\}$ & $\{2\}$ & $\{1\}$ \\
$x_{3}$ & $\{2,3\}$ & $\{1\}$ & $\{1\}$ & $\{3\}$ \\
$x_{4}$ & $\{1\}$ & $\{2\}$ & $\{1,3\}$ & $\{1\}$ \\
$x_{5}$ & $\{2,3\}$ & $\{1,2\}$ & $\{2\}$ & $\{3\}$ \\
$x_{6}$ & $\{3\}$ & $\{1,2\}$ & $\{1\}$ & $\{1,2\}$ \\
$x_{7}$ & $\{3\}$ & $\{2\}$ & $\{1,2\}$ & $\{2,3\}$ \\
$x_{8}$ & $\{3\}$ & $\{2\}$ & $\{2\}$ & $\{1,3\}$ \\
\hline
\end{tabular}

Based on the Table 3, all the elementary information granules can be got as follows:

$g_{1}^{a_{1}}=\left\{x_{1}, x_{4}\right\}, g_{2}^{a_{1}}=\left\{x_{2}, x_{3}, x_{5}\right\}, g_{3}^{a_{1}}=\left\{x_{3}, x_{5}, x_{6}, x_{7}, x_{8}\right\} ; g_{1}^{a_{2}}=\left\{x_{2}, x_{3}, x_{5}, x_{6}\right\}, g_{2}^{a_{2}}=\left\{x_{1}, x_{2}, x_{4}, x_{5}, x_{6}, x_{7}, x_{8}\right\} ; g_{1}^{a_{3}}=$ $\left\{x_{1}, x_{3}, x_{4}, x_{6}, x_{7}\right\}, g_{2}^{a_{3}}=\left\{x_{2}, x_{5}, x_{7}, x_{8}\right\}, g_{3}^{a_{3}}=\left\{x_{1}, x_{4}\right\} ; g_{1}^{a_{4}}=\left\{x_{1}, x_{2}, x_{4}, x_{6}, x_{8}\right\}, g_{2}^{a_{4}}=\left\{x_{6}, x_{7}\right\}, g_{3}^{a_{4}}=\left\{x_{3}, x_{5}, x_{7}, x_{8}\right\}$.

According to these elementary information granules, several special granular structures can be induced as follows:

(1) The partition of $O B$ with respect to $A T$ :

$\mathcal{P}_{A T}=\left\{\left\{x_{1}, x_{4}\right\},\left\{x_{2}\right\},\left\{x_{3}\right\},\left\{x_{5}\right\},\left\{x_{6}\right\},\left\{x_{7}\right\},\left\{x_{8}\right\}\right\} ;$

(2) The multi-partition of $O B$ with respect to $A T$ :

$\mathbb{P}_{A T}=\left\{P_{a_{1}}, P_{a_{2}}, P_{a_{3}}, P_{a_{4}}\right\}$

$=\left\{\left\{\left\{x_{1}, x_{4}\right\},\left\{x_{2}\right\},\left\{x_{3}, x_{5}\right\},\left\{x_{6}, x_{7}, x_{8}\right\}\right\},\left\{\left\{x_{1}, x_{4}, x_{7}, x_{8}\right\},\left\{x_{3}\right\},\left\{x_{2}, x_{5}, x_{6}\right\}\right\},\left\{\left\{x_{1}, x_{4}\right\},\left\{x_{2}, x_{5}, x_{8}\right\},\left\{x_{3}, x_{6}\right\},\left\{x_{7}\right\}\right\}\right.$,

$\left.\left\{\left\{x_{1}, x_{2}, x_{4}\right\},\left\{x_{3}, x_{5}\right\},\left\{x_{6}\right\},\left\{x_{7}\right\},\left\{x_{8}\right\}\right\}\right\}$;

(3) The multi-covering of $O B$ with respect to $A T$ :

$\mathbb{C}_{A T}=\left\{C_{a_{1}}, C_{a_{2}}, C_{a_{3}}, C_{a_{4}}\right\}$

$=\left\{\left\{\left\{x_{1}, x_{4}\right\},\left\{x_{2}\right\},\left\{x_{3}, x_{5}\right\},\left\{x_{2}, x_{3}, x_{5}\right\},\left\{x_{6}, x_{7}, x_{8}\right\},\left\{x_{3}, x_{5}, x_{6}, x_{7}, x_{8}\right\}\right\},\left\{\left\{x_{1}, x_{4}, x_{7}, x_{8}\right\},\left\{x_{3}\right\},\left\{x_{2}, x_{5}, x_{6}\right\},\left\{x_{2}, x_{3}, x_{5}, x_{6}\right\}\right.\right.$, $\left.\left\{x_{1}, x_{2}, x_{4}, x_{5}, x_{6}, x_{7}, x_{8}\right\}\right\},\left\{\left\{x_{1}, x_{3}, x_{4}, x_{6}, x_{7}\right\},\left\{x_{1}, x_{4}\right\},\left\{x_{2}, x_{5}, x_{8}\right\},\left\{x_{3}, x_{6}\right\},\left\{x_{7}\right\},\left\{x_{2}, x_{5}, x_{7}, x_{8}\right\}\right\},\left\{\left\{x_{1}, x_{2}, x_{4}\right\},\left\{x_{3}, x_{5}\right\}\right.$, $\left.\left.\left\{x_{6}\right\},\left\{x_{7}\right\},\left\{x_{8}\right\},\left\{x_{1}, x_{2}, x_{4}, x_{6}, x_{8}\right\},\left\{x_{6}, x_{7}\right\},\left\{x_{3}, x_{5}, x_{7}, x_{8}\right\}\right\}\right\}$ 
(4) The covering of $O B$ with respect to $A T$ :

$C_{A T}=\left\{\left\{x_{1}, x_{4}\right\},\left\{x_{2}\right\},\left\{x_{3}\right\},\left\{x_{5}\right\},\left\{x_{6}\right\},\left\{x_{7}\right\},\left\{x_{8}\right\},\left\{x_{5}, x_{7}, x_{8}\right\},\left\{x_{6}, x_{7}\right\},\left\{x_{7}, x_{8}\right\}\right\}$.

\subsection{The relationship among the rough set models induced by the set-valued information systems}

Here, we will focus on the inclusion relationship among the upper and lower approximation sets in the rough set models obtained from the set-valued information system.

Proposition 5.1 Suppose that $I=\left(O B, A T,\left\{V_{a} \mid a \in A T\right\},\left\{f_{a} \mid a \in A T\right\}\right)$ is a set-valued information system. For any $X \subseteq O B$, the following results hold.

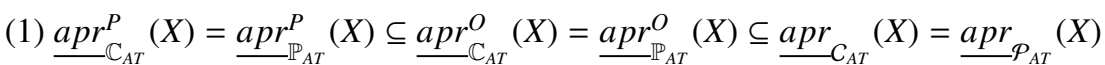

(2) $\overline{\operatorname{apr}}_{\mathcal{P}_{A T}}(X)=\overline{a p r}_{C_{A T}}(X) \subseteq \overline{\operatorname{apr}}_{\mathbb{P}_{A T}}^{O}(X)=\overline{a p r}_{\mathbb{C}_{A T}}^{O}(X) \subseteq \overline{\operatorname{apr}}_{\mathbb{P}_{A T}}^{P}(X)=\overline{a p r}_{\mathbb{C}_{A T}}^{P}(X)$

Proof. It is easy to be proved by equations (8)-(11).

Example 5.2 (Continued from Example 5.1) For $X=\left\{x_{5}, x_{6}, x_{8}\right\}$, we have that $\operatorname{apr}_{\mathbb{C}_{A T}^{P}}^{P}(X)=\underline{a^{2} r^{P}} \mathbb{P}_{A T}(X)=\emptyset$,

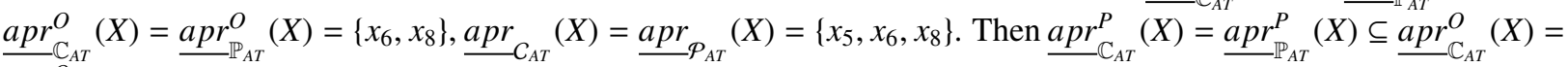
$\underline{\operatorname{apr}} \underline{P}_{A T}^{O}(X) \subseteq \underline{\operatorname{apr}}_{C_{A T}}(X)=\underline{\operatorname{apr}}_{\mathcal{P}_{A T}}(X)$.

Meanwhile, for $Y=\left\{x_{2}, x_{3}, x_{4}, x_{7}\right\}$, we can get $\overline{a p r}_{\mathcal{P}_{A T}}(Y)=\overline{a p r}_{C_{A T}}(Y)=\left\{x_{1}, x_{2}, x_{3}, x_{4}, x_{7}\right\}, \overline{a p r}_{\mathbb{P}_{A T}}^{O}(Y)=\overline{a p r}_{\mathbb{C}_{A T}}^{O}(Y)$ $=\left\{x_{1}, x_{2}, x_{3}, x_{4}, x_{5}, x_{7}\right\}, \overline{a p r}_{\mathbb{P}_{A T}}^{P}(Y)=\overline{\operatorname{apr}}_{\mathbb{C}_{A T}}^{P}(Y)=O B$. So, $\overline{\operatorname{apr}}_{\mathcal{P}_{A T}}(Y)=\overline{a p r}_{C_{A T}}(Y) \subseteq \overline{\operatorname{apr}}_{\mathbb{P}_{A T}}^{O}(Y)=\overline{a p r}_{\mathbb{C}_{A T}}^{O}(Y) \subseteq$ $\overline{\operatorname{apr}}_{\mathbb{P}_{A T}}^{P}(Y)=\overline{\operatorname{apr}}_{\mathbb{C}_{A T}}^{P}(Y)$.

\subsection{The relationship among the reductions induced by the set-valued information systems}

Based on the set-valued information system, four kinds of granular structures can be induced. In this part, we first add a concept of attribute reduction based on covering granular structure, and then comparatively study the relationship among the reductions based on these granular structures.

Definition 5.1 Suppose that $I=\left(O B, A T,\left\{V_{a} \mid a \in A T\right\},\left\{f_{a} \mid a \in A T\right\}\right)$ is a set-valued information system and $C_{A T}$ is the covering of $O B$ with respect to $A T$. For any $a \in A T$, one can find that $\mathcal{P}_{A T} \subseteq C_{A T /\{a\}}$, then $a$ is called the reducible attribute of $A T$ with respect to $C_{A T}$, and denoted by $a_{\text {reduct }}$ C $_{A T}$. If $A T^{\prime} \subseteq A T$ meets two conditions: (1) for any $a \in A T / A T^{\prime}, a$ is the reducible attribute of $A T$ with respect to $C_{A T}$; (2) for any $a \in A T^{\prime}, a$ is not the reducible attribute of $A T$ with respect to $C_{A T}$. Then $A T^{\prime}$ is called the reduct of $A T$ with respect to $C_{A T}$, and denoted by $\operatorname{reduct}(A T)_{C_{A T}}$.

Definition 5.2 Suppose $I=\left(O B, A T,\left\{V_{a} \mid a \in A T\right\},\left\{f_{a} \mid a \in A T\right\}\right)$ is a set-valued information system and $\mathbb{C}_{A T}=$ $\left\{C_{a_{1}}, C_{a_{2}}, \cdots, C_{a_{m}}\right\}$ is a family of the coverings of $O B$ with respect to $A T$. Then we call $\left\{\operatorname{reduct}\left(C_{a_{1}}\right)_{\cup}, \operatorname{reduct}\left(C_{a_{2}}\right)_{\cup}, \cdots\right.$, $\left.\operatorname{reduct}\left(C_{a_{m}}\right) \cup\right\}$ the union reduct of $\mathbb{C}_{A T}$, and denoted by reduct $\left(\mathbb{C}_{A T}\right)_{\cup}$. Meanwhile, we call $\left\{\operatorname{reduct}\left(C_{a_{1}}\right)_{\cap}, \operatorname{reduct}\left(C_{a_{2}}\right)_{\cap}\right.$, $\left.\cdots, \operatorname{reduct}\left(C_{a_{m}}\right)_{\cap}\right\}$ the intersection reduct of $\mathbb{C}_{A T}$, and denoted by $\operatorname{reduct}\left(\mathbb{C}_{A T}\right)_{\cap}$.

Definition 5.3 Suppose $I=\left(O B, A T,\left\{V_{a} \mid a \in A T\right\},\left\{f_{a} \mid a \in A T\right\}\right)$ is a set-valued information system and $\mathbb{C}_{A T}=$ $\left\{C_{a_{1}}, C_{a_{2}}, \cdots, C_{a_{m}}\right\}$ is a family of the coverings of $O B$ with respect to $A T$. For any $a \in A T$ and any $g \in C_{a} \in \mathbb{C}_{A T}$, if there exist $\mathbb{C}_{A T}^{\prime} \subseteq \mathbb{C}_{A T} /\left\{C_{a}\right\}$ and $\mathcal{K}^{\prime} \subseteq \widetilde{\mathcal{K}} \in \mathbb{C}_{A T}^{\prime}$ such that $K=\cup_{\widetilde{\mathcal{K}} \in \mathbb{C}_{A T}^{\prime}}\left(\cup_{\mathcal{K}^{\prime} \subseteq \widetilde{\mathcal{K}}} \mathcal{K}^{\prime}\right)\left(\right.$ or $\left.K=\cap_{\widetilde{\mathcal{K}} \in \mathbb{C}_{A T}^{\prime}}\left(\cap_{\mathcal{K}^{\prime} \in \widetilde{\mathcal{K}}} \mathcal{K}^{\prime}\right)\right)$, then $a$ is called the union ( or intersection ) reducible attribute of $A T$ with respect to $\mathbb{C}_{A T}$, and $a$ is denoted by $a_{\text {reduct }} \mathbb{C}_{A T}, \cup$ ( or $a_{\text {reduct } \mathbb{C}_{A T} \cap \text { ) }}$ ). Otherwise, $a$ is called the union ( or intersection ) irreducible attribute of $A T$ with respect to $\mathbb{C}_{A T}$. If $A T^{\prime} \subseteq A T$ meets two conditions: (1) for any $a \in A T / A T^{\prime}, a$ is the union ( or intersection ) reducible attribute of $A T$ with respect to $\mathbb{C}_{A T}$; (2) for any $a \in A T^{\prime}, a$ is not the union ( or intersection ) reducible attribute of $A T$ with respect to $\mathbb{C}_{A T}$. Then $A T^{\prime}$ is called the union ( or intersection ) reduction of $A T$ with respect to $\mathbb{C}_{A T}$, and denoted by $\operatorname{reduct}(A T)_{\mathbb{C}_{A T}, \cup}\left(\right.$ or $\left.\operatorname{reduct}(A T)_{\mathbb{C}_{A T}, \cap}\right)$.

According to the definition of each rough set model and the reduction of the related granular structure, it is easy to see that the conclusions of propositions 5.2-5.6 are true. So the proof of these propositions is omitted.

Proposition 5.2 Suppose that $I=\left(O B, A T,\left\{V_{a} \mid a \in A T\right\},\left\{f_{a} \mid a \in A T\right\}\right)$ is a set-valued information system. For any $X \subseteq O B$, the following results hold.

(1) $\underline{\operatorname{apr}}_{\operatorname{reduct}\left(\mathcal{P}_{A T}\right)}(X)=\underline{\operatorname{apr}}_{\mathcal{P}_{A T}}(X), \overline{\operatorname{apr}}_{\text {reduct }\left(\mathcal{P}_{A T}\right)}(X)=\overline{\operatorname{apr}}_{\mathcal{P}_{A T}}(X)$; 
(2) $\underline{\operatorname{apr}}_{\text {reduct }\left(C_{A T}\right) \cup}(X)=\underline{\operatorname{apr}}_{C_{A T}}(X), \overline{\operatorname{apr}}_{\text {reduct }\left(C_{A T}\right) \cup}(X)=\overline{a p r}_{C_{A T}}(X)$;

(3) $\underline{\operatorname{apr}}_{\operatorname{reduct}(A T)_{\mathcal{C}_{A T}}}(X)=\underline{\operatorname{apr}}_{C_{A T}}(X), \overline{a p r}_{\text {reduct }(A T) \mathcal{C}_{A T}}(X)=\overline{a p r}_{C_{A T}}(X)$;

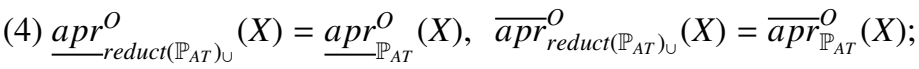

(5) $\underline{\operatorname{apr}}_{\text {reduct }\left(\mathbb{P}_{A T}\right)_{n}}(X)=\underline{\operatorname{apr}}_{\mathbb{P}_{A T}^{P}}^{P}(X), \overline{\operatorname{apr}}{ }_{\text {reduct }\left(\mathbb{P}_{A T}\right)_{n}}(X)=\overline{\operatorname{apr}}_{\mathbb{P}_{A T}}^{P}(X)$;

(6) $\underline{\operatorname{apr}}_{\text {reduct }\left(\mathbb{C}_{A T}\right)}^{O}(X)=\underline{\operatorname{apr}}{\underline{\mathbb{C}_{A T}}}_{(X),}(X) \overline{a p r}_{\text {reduct }\left(\mathbb{C}_{A T}\right) \cup}^{O}(X)=\overline{\operatorname{apr}}_{\mathbb{C}_{A T}}^{O}(X)$;

(7) $\underline{a p r}_{\text {reduct }\left(\mathbb{C}_{A T}\right) \cup}(X)=\underline{\operatorname{apr}}{\underline{\mathbb{C}_{A T}}}^{P}(X), \overline{\operatorname{apr}}{ }_{\text {reduct }\left(\mathbb{C}_{A T}\right) \cup}(X)=\overline{a p r}_{\mathbb{C}_{A T}}^{P}(X)$;

(8) $\underline{a p r}_{\text {reduct }\left(\mathbb{C}_{A T}\right)}^{O}(X)=\underline{a p r}{\underline{\mathbb{C}_{A T}}}_{(X),}(X) \overline{a p r}_{\text {reduct }\left(\mathbb{C}_{A T}\right) \cup}^{O}(X)=\overline{a p r}_{\mathbb{C}_{A T}}^{O}(X)$;

(9) $\underline{\operatorname{apr}}_{\text {reduct }\left(\mathbb{C}_{A T}\right)_{n}}(X)=\underline{\operatorname{apr} \underline{\mathbb{C}}_{A T}^{P}}(X), \overline{\operatorname{apr}}{ }_{\text {reduct }\left(\mathbb{C}_{A T}\right)_{n}}^{P}(X)=\overline{\operatorname{apr}}_{\mathbb{C}_{A T}}^{P}(X)$.

Proposition 5.3 Suppose that $I=\left(O B, A T,\left\{V_{a} \mid a \in A T\right\},\left\{f_{a} \mid a \in A T\right\}\right)$ is a set-valued information system. For any $X \subseteq O B$, the following results hold.
(1) $\underline{\operatorname{apr}}_{\text {reduct }\left(C_{A T}\right)_{n}}(X) \subseteq \underline{\operatorname{apr}}_{C_{A T}}(X), \overline{\operatorname{apr}}_{\text {reduct }\left(C_{A T}\right)_{\cap}}(X) \supseteq \overline{a p r}_{C_{A T}}(X)$;
(2) $\underline{\operatorname{apr}}_{\text {reduct }\left(\mathbb{P}_{A T}\right) \cup}^{P}(X) \supseteq \underline{\operatorname{apr}}_{\mathbb{P}_{A T}}^{P}(X), \overline{\operatorname{apr}}_{\text {reduct }\left(\mathbb{P}_{A T}\right)}^{P}(X) \subseteq \overline{\operatorname{apr}}_{\mathbb{P}_{A T}}^{P}(X)$;
(3) $\underline{\operatorname{apr}}_{\text {reduct }\left(\mathbb{O}_{A T}\right)_{n}}^{P}(X) \subseteq \underline{\operatorname{apr}}_{\mathbb{P}_{A T}}^{O}(X), \overline{\operatorname{apr}}_{\text {reduct }\left(\mathbb{P}_{A T}\right)_{n}}^{O}(X) \supseteq \overline{\operatorname{apr}}_{\mathbb{P}_{A T}}^{O}(X)$;
(4) $\underline{a p r}_{\text {reduct }\left(\mathbb{C}_{A T}\right)_{n}}^{O}(X) \subseteq \underline{a p r}_{\mathbb{C}_{A T}}^{O}(X), \overline{a p r}_{\text {reduct }\left(\mathbb{C}_{A T}\right)_{n}}^{O}(X) \supseteq \overline{a p r}_{\mathbb{C}_{A T}}^{O}(X)$;
(5) $\underline{\operatorname{apr}}_{\text {reduct }\left(\mathbb{C}_{A T}\right)_{n}}(X) \subseteq \underline{\operatorname{apr}}{\underline{\mathbb{C}_{A T}}}^{P}(X), \overline{\operatorname{apr}}_{\text {reduct }\left(\mathbb{C}_{A T}\right)_{n}}(X) \supseteq \overline{\operatorname{apr}}_{\mathbb{C}_{A T}}^{P}(X)$;
(6) $\underline{\operatorname{apr}}_{\text {reduct }\left(\mathbb{C}_{A T}\right)_{\cup}}(X) \supseteq \underline{\operatorname{apr} \underline{\mathbb{C}}_{A T}^{P}}(X), \overline{\operatorname{apr}}_{\text {reduct }\left(\mathbb{C}_{A T}\right) \cup}(X) \subseteq \overline{\operatorname{apr}}_{\mathbb{C}_{A T}}^{P}(X)$;
(7) $\underline{\operatorname{apr}}_{\text {reduct }\left(\mathbb{C}_{A T}\right)_{n}}^{O}(X) \subseteq \underline{\operatorname{apr}}{\underline{\mathbb{C}_{A T}}}_{(X),}(X) \overline{\operatorname{apr}}_{\text {reduct }\left(\mathbb{C}_{A T}\right)_{n}}^{O}(X) \supseteq \overline{\operatorname{apr}}_{\mathbb{C}_{A T}}^{O}(X)$.

Proposition 5.4 Suppose that $I=\left(O B, A T,\left\{V_{a} \mid a \in A T\right\},\left\{f_{a} \mid a \in A T\right\}\right)$ is a set-valued information system and $C_{A T}$ is a covering of $O B$ with respect to $A T$. For any $X \subseteq O B$, the following results hold.
(1) $\underline{\operatorname{apr}}_{\operatorname{reduct}\left(\mathcal{C}_{A T}\right)_{n}}(X) \subseteq \underline{\operatorname{apr}}_{\operatorname{reduct}\left(\mathcal{C}_{A T}\right)}(X)=\underline{\operatorname{apr}}_{\operatorname{reduct}(A T)_{\mathcal{C}_{A T}}}(X)$;
(2) $\overline{\operatorname{apr}}_{\text {reduct }(A T)_{\mathcal{C}_{A T}}}(X)=\overline{\operatorname{apr}}_{\text {reduct }\left(C_{A T}\right)}(X) \subseteq \overline{\operatorname{apr}}_{\text {reduct }\left(C_{A T}\right)_{n}}(X)$.

Proposition 5.5 Suppose that $I=\left(O B, A T,\left\{V_{a} \mid a \in A T\right\},\left\{f_{a} \mid a \in A T\right\}\right)$ is a set-valued information system and $\mathbb{P}_{A T}$ is a multi-partition of $O B$ with respect to $A T$. For any $X \subseteq O B$, the following results hold.
(1) $\operatorname{apr}_{\operatorname{reduct}(A T)_{\mathbb{P}_{A T}, \cap}^{P}}^{P}(X) \subseteq \underline{\operatorname{apr}}_{\operatorname{reduct}(A T)_{\mathbb{P}_{A T}, \cup}^{P}}^{P}(X) \subseteq \underline{\operatorname{apr}}_{\operatorname{reduct}(A T)_{\mathbb{P}_{A}, \cup}^{O}}^{O}(X)$;

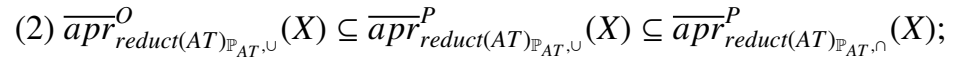

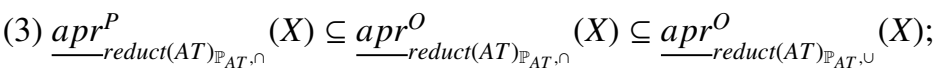
(4) $\overline{\operatorname{apr}}_{\text {reduct }(A T)_{\mathbb{P}_{A}, U}}^{O}(X) \subseteq \overline{\operatorname{apr}}_{\text {reduct }(A T)_{\mathbb{P}_{A}, \cap}}^{O}(X) \subseteq \overline{\operatorname{apr}}_{\text {reduct }(A T)_{\mathbb{P}_{A T}, \cap}}^{P}(X)$.

Proposition 5.6 Suppose that $I=\left(O B, A T,\left\{V_{a} \mid a \in A T\right\},\left\{f_{a} \mid a \in A T\right\}\right)$ is a set-valued information system and $\mathbb{C}_{A T}$ is a multi-partition of $O B$ with respect to $A T$. For any $X \subseteq O B$, the following results hold.

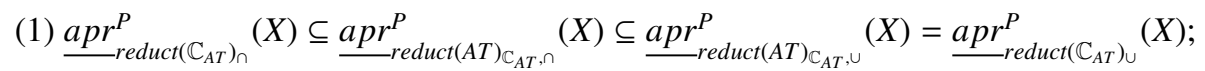
(2) $\overline{\operatorname{apr}}_{\text {reduct }\left(\mathbb{C}_{A T}\right) \cup}^{P}(X)=\overline{\operatorname{apr}}_{\text {reduct }(A T)_{\mathrm{C}_{A T}, \cup}}^{P}(X) \subseteq \overline{\operatorname{apr}}_{\text {reduct }(A T) \mathrm{C}_{A T,},}^{P}(X) \subseteq \overline{\operatorname{apr}}_{\text {reduct }\left(\mathbb{C}_{A T}\right)_{\cap}}^{P}(X)$;

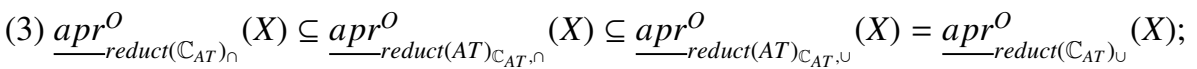

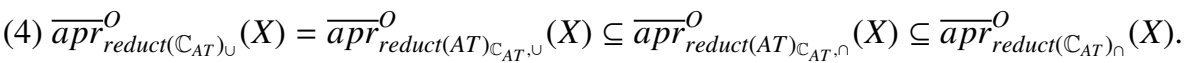

The following two propositions show the relationship among the attribute reductions of different granular structures proposed above. 
Proposition 5.7 Suppose that $I=\left(O B, A T,\left\{V_{a} \mid a \in A T\right\},\left\{f_{a} \mid a \in A T\right\}\right)$ is a set-valued information system. Then the following results hold.

(1) $\operatorname{reduct}\left(C_{A T}\right) \cup=\mathcal{P}_{A T}$;

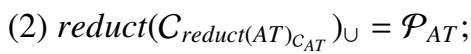

(3) $\operatorname{reduct}\left(\mathbb{C}_{A T}\right)_{\cup}=\mathbb{P}_{A T}$;

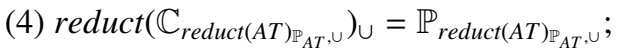

Proof. (1) suppose that $C_{A T}=\left\{K_{1}, K_{2}, \cdots, K_{t}\right\}$ is the covering of $O B$ with respect to $A T$. Then for any $K \in C_{A T}$, there exist $K_{i}^{\prime} \in C_{a_{1}} \in \mathbb{C}_{A T}, i=1,2 . \cdots, m$ such that $K=K_{1}^{\prime} \cap K_{2}^{\prime} \cap \cdots \cap K_{m}^{\prime}$. Since $C_{a_{i}}=\mathcal{P}_{a_{i}} \cup C_{a_{i}}^{\prime}$, if $C_{a_{i}}^{\prime}=\emptyset$, then one can find that there are $P_{i} \in \mathcal{P}_{a_{i}} \in \mathbb{P}_{A T}, i=1,2, \cdots, m$ so that $K=P_{1} \cap P_{2} \cap \cdots \cap P_{m}$. That is to say that $\mathcal{P}_{A T} \subseteq C_{A T}$. In addition, based on the structure of $C_{a_{i}}^{\prime}$, for each $K^{\prime \prime} \in C_{a_{i}}^{\prime} / \mathcal{P}_{a_{i}}$, there is $\mathcal{P} \subseteq \mathcal{P}_{A T}$ so that $K^{\prime \prime}=\cup_{P \in \mathcal{P}} P$. In conclusion, equation $\operatorname{reduct}\left(C_{A T}\right)_{\cup}=\mathcal{P}_{A T}$ holds.

(2) Based on Definition 5.1, one can find that $\mathcal{P}_{A T} \subseteq \mathcal{C}_{\text {reduct }(A T)_{\mathcal{C}_{A T}}}$. At the same time, the relation $C_{\text {reduct }(A T)_{\mathcal{C}_{A T}} \subseteq}$

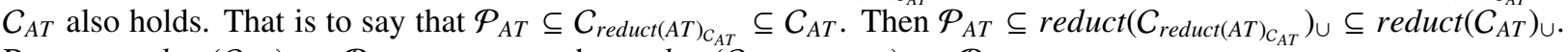
Because $\operatorname{reduct}\left(C_{A T}\right)_{\cup}=\mathcal{P}_{A T}$, we can get that reduct $\left(C_{\text {reduct }(A T)_{C_{A T}}}\right) \cup=\mathcal{P}_{A T}$.

(3) According to the structures of $\mathbb{C}_{A T}$ and $\mathbb{P}_{A T}$, the conclusion is obvious.

(4) Based on the third conclusion in this proposition, the result obviously holds.

Proposition 5.8 Suppose that $I=\left(O B, A T,\left\{V_{a} \mid a \in A T\right\},\left\{f_{a} \mid a \in A T\right\}\right)$ is a set-valued information system. If $a \in A T$ is a reducible attribute of $A T$ with respect to $\mathcal{P}_{A T}$ if and only if $a \in A T$ is a reducible attribute of $A T$ with respect to $C_{A T}$.

Proof. ( $\Rightarrow$ :) Since $a \in A T$ is a reducible attribute of $A T$ with respect to $\mathcal{P}_{A T}$, then $\mathcal{P}_{A T /\{a\}}=\mathcal{P}_{A T}$. Meanwhile, based on the construction of $C_{A T}$, we have that $\mathcal{P}_{A T /\{a\}} \subseteq C_{A T /\{a\}}$. Then we can get that $\mathcal{P}_{A T} \subseteq C_{A T /\{a\}}$. Therefore, $a \in A T$ is a reducible attribute of $A T$ with respect to $C_{A T}$.

$(\Leftarrow:)$ If $a \in A T$ is a reducible attribute of $A T$ with respect to $\mathcal{C}_{A T}$, then $\mathcal{P}_{A T} \subseteq C_{A T /\{a\}}$. This shows that $\mathcal{P}_{A T /\{a\}}=$ $\mathcal{P}_{A T}$. So, $a \in A T$ is a reducible attribute of $A T$ with respect to $\mathcal{P}_{A T}$.

Proposition 5.9 Suppose that $I=\left(O B, A T,\left\{V_{a} \mid a \in A T\right\},\left\{f_{a} \mid a \in A T\right\}\right)$ is a set-valued information system. If $a \in A T$ is a union or an intersection reducible attribute of $A T$ with respect to $\mathbb{P}_{A T}$, then $a \in A T$ is a reducible attribute of $A T$ with respect to $\mathcal{P}_{A T}$;

Proof. The proof of this proposition is similar to that of the first conclusion in Proposition 3.7.

Proposition 5.10 Suppose that $I=\left(O B, A T,\left\{V_{a} \mid a \in A T\right\},\left\{f_{a} \mid a \in A T\right\}\right)$ is a set-valued information system. If $a \in A T$ is the intersection reducible attribute of $A T$ with respect to $\mathbb{C}_{A T}$, then $a \in A T$ is the reducible attribute of $A T$ with respect to $\mathcal{P}_{A T}$.

Proof. For each $g \in \mathcal{P}_{A T}$, there are $P_{i} \in \mathcal{P}_{a_{i}} \in \mathbb{P}_{A T}$ so that $g=P_{1} \cap P_{2} \cap \cdots \cap P_{m}$. Without loss of generality, suppose that $a_{1} \in A T$ is the intersection reducible attribute of $A T$ with respect to $\mathbb{C}_{A T}$. Then there exist $\mathbb{C}_{A T}^{\prime} \subseteq \mathbb{C}_{A T} /\left\{C_{a_{1}}\right\}$ and $K^{\prime} \subseteq \widetilde{K} \in \mathbb{C}_{A T}^{\prime}$ such that $P_{1}=\cap_{\widetilde{K} \in \mathbb{C}_{A T}^{\prime}}\left(\cap_{K^{\prime} \in \widetilde{K}} K^{\prime}\right)$. Let's mark $\cup \mathbb{C}_{A T}^{\prime}=\left\{K_{1}, K_{2}, \cdots, K_{l}\right\}$. So $g=P_{1} \cap P_{2} \cap \cdots \cap P_{m}=$ $\left(K_{1} \cap K_{2} \cap \cdots \cap K_{l}\right) \cap\left(P_{2} \cap P_{3} \cap \cdots \cap P_{m}\right)$. Based on the structures of $K_{j}, j=1,2, \cdots, l$, for each $K_{j}$, one can find that there is $P_{i}$ such that $P_{i} \subseteq K_{j}$. Then $g=P_{2} \cap \cdots \cap P_{m}$. Therefore, $a \in A T$ is the reducible attribute of $A T$ with respect to $\mathcal{P}_{A T}$.

Proposition 5.11 Suppose that $I=\left(O B, A T,\left\{V_{a} \mid a \in A T\right\},\left\{f_{a} \mid a \in A T\right\}\right)$ is a set-valued information system. $a \in A T$ is a union reducible attribute of $A T$ with respect to $\mathbb{P}_{A T}$ if and only if $a \in A T$ is a union reducible attribute of $A T$ with respect to $\mathbb{C}_{A T}$.

Proof. ( $\Rightarrow$ :) Obviously.

$(\Leftarrow:)$ For each $P \in \mathcal{P}_{a} \in \mathbb{P}_{A T}$, it can be found that $P \in C_{a} \in \mathbb{C}_{A T}$. If $a \in A T$ is a union reducible attribute of $A T$ with respect to $\mathbb{C}_{A T}$, then there exists $\mathcal{K}=\left\{K_{1}, K_{2}, \cdots, K_{p}\right\} \subseteq \cup \mathbb{C}_{A T}$ such that $P=K_{1} \cup K_{2} \cup \cdots \cup K_{p}$, where $K_{i} \bar{\in} C_{a}, i=1,2, \cdots, p$. According to the definition of $\mathbb{C}_{A T}$, for each $K \in \mathcal{K}$, one can find that an attribute $a^{\prime} \in A T /\{a\}$ and a subset family $\widetilde{\mathcal{P}}_{a^{\prime}} \subseteq \mathcal{P}_{a^{\prime}}$ so that $K=\cup \widetilde{\mathcal{P}}_{a^{\prime}}$. That is to say that $K$ is the union of some sets in $\mathcal{P}_{a^{\prime}}$. Then, $P$ is the 
union of some sets in $\cup \mathbb{P}_{A T /\{a\}}$. Therefore, we know that $a \in A T$ is a union reducible attribute of $A T$ with respect to $\mathbb{P}_{A T}$.

From Proposition 5.11, we know that $a \in A T$ is a union reducible attribute of $A T$ with respect to $\mathbb{P}_{A T}$ if and only if $a \in A T$ is a union reducible attribute of $A T$ with respect to $\mathbb{C}_{A T}$. What is the relationship between the intersection reducible attribute of $A T$ with respect to $\mathbb{P}_{A T}$ and $\mathbb{C}_{A T}$ ? Next, let's use Examples 5.4 and 5.5 to answer this question.

Example 5.4 Suppose that $I=\left(O B, A T,\left\{V_{a} \mid a \in A T\right\},\left\{f_{a} \mid a \in A T\right\}\right)$ is a set-valued information system. The details are shown in Table 4.

Based on the Table 4,

$$
\mathbb{P}_{A T}=\left\{\mathcal{P}_{a_{1}}, \mathcal{P}_{a_{2}}, \mathcal{P}_{a_{3}}\right\}
$$

where

$$
\begin{gathered}
\mathcal{P}_{a_{1}}=\left\{\left\{x_{1}, x_{4}\right\},\left\{x_{2}, x_{5}\right\},\left\{x_{3}\right\},\left\{x_{6}\right\},\left\{x_{7}\right\},\left\{x_{8}\right\}\right\}, \\
\mathcal{P}_{a_{2}}=\left\{\left\{x_{1}, x_{4}\right\},\left\{x_{2}, x_{3}, x_{5}\right\},\left\{x_{6}, x_{7}\right\},\left\{x_{8}\right\}\right\}, \\
\mathcal{P}_{a_{3}}=\left\{\left\{x_{1}, x_{3}, x_{4}\right\},\left\{x_{2}, x_{5}, x_{7}\right\},\left\{x_{6}, x_{8}\right\}\right\} . \\
\mathbb{C}_{A T}=\left\{C_{a_{1}}, C_{a_{2}}, C_{a_{3}}\right\}
\end{gathered}
$$

where

$$
\begin{gathered}
C_{a_{1}}=\left\{\left\{x_{1}, x_{4}\right\},\left\{x_{2}, x_{5}\right\},\left\{x_{3}\right\},\left\{x_{6}\right\},\left\{x_{7}\right\},\left\{x_{8}\right\},\left\{x_{1}, x_{4}, x_{6}, x_{8}\right\},\left\{x_{2}, x_{3}, x_{4}, x_{5}\right\},\left\{x_{3}, x_{6}, x_{7}\right\}\right\}, \\
C_{a_{2}}=\left\{\left\{x_{1}, x_{4}\right\},\left\{x_{2}, x_{3}, x_{5}\right\},\left\{x_{6}, x_{7}\right\},\left\{x_{8}\right\},\left\{x_{2}, x_{3}, x_{5}, x_{6}, x_{7}\right\},\left\{x_{1}, x_{2}, x_{3}, x_{4}, x_{5}, x_{8}\right\},\left\{x_{1}, x_{4}, x_{6}, x_{7}\right\}\right\}, \\
C_{a_{3}}=\left\{\left\{x_{1}, x_{3}, x_{4}\right\},\left\{x_{2}, x_{5}, x_{7}\right\},\left\{x_{6}, x_{8}\right\},\left\{x_{1}, x_{3}, x_{4}, x_{6}, x_{8}\right\},\left\{x_{1}, x_{2}, x_{3}, x_{4}, x_{5}, x_{7}\right\},\left\{x_{2}, x_{5}, x_{6}, x_{7}, x_{8}\right\}\right\} .
\end{gathered}
$$

Clearly, $a_{1} \in A T$ is an intersection reducible attribute of $A T$ with respect to $\mathbb{P}_{A T}$, but $a_{1} \in A T$ is not the intersection reducible attribute of $A T$ with respect to $\mathbb{C}_{A T}$.

Table 4. A set-valued information table

\begin{tabular}{c|ccc}
\hline$O B$ & $a_{1}$ & $a_{2}$ & $a_{3}$ \\
\hline$x_{1}$ & $\{1,2\}$ & $\{2,3\}$ & $\{1,2\}$ \\
$x_{2}$ & $\{2\}$ & $\{1,2\}$ & $\{2,3\}$ \\
$x_{3}$ & $\{2,3\}$ & $\{1,2\}$ & $\{1,2\}$ \\
$x_{4}$ & $\{1,2\}$ & $\{2,3\}$ & $\{1,2\}$ \\
$x_{5}$ & $\{2\}$ & $\{1,2\}$ & $\{2,3\}$ \\
$x_{6}$ & $\{1,3\}$ & $\{1,3\}$ & $\{1,3\}$ \\
$x_{7}$ & $\{3\}$ & $\{1,3\}$ & $\{2,3\}$ \\
$x_{8}$ & $\{1\}$ & $\{2\}$ & $\{1,3\}$ \\
\hline
\end{tabular}

Example 5.5 Suppose that $I=\left(O B, A T,\left\{V_{a} \mid a \in A T\right\},\left\{f_{a} \mid a \in A T\right\}\right)$ is a set-valued information system. The details are shown in the Table 5.

Table 5. A set-valued information table

\begin{tabular}{c|ccc}
\hline$O B$ & $a_{1}$ & $a_{2}$ & $a_{3}$ \\
\hline$x_{1}$ & $\{1\}$ & $\{1,2\}$ & $\{1\}$ \\
$x_{2}$ & $\{2\}$ & $\{3\}$ & $\{2,4\}$ \\
$x_{3}$ & $\{2\}$ & $\{3,4\}$ & $\{1\}$ \\
$x_{4}$ & $\{1\}$ & $\{1,2\}$ & $\{1\}$ \\
$x_{5}$ & $\{2\}$ & $\{3\}$ & $\{2,4\}$ \\
$x_{6}$ & $\{3\}$ & $\{1,4\}$ & $\{3,4\}$ \\
$x_{7}$ & $\{3\}$ & $\{1,4\}$ & $\{2,4\}$ \\
$x_{8}$ & $\{3,4\}$ & $\{1\}$ & $\{3,4\}$ \\
\hline
\end{tabular}


Based on the Table 4,

$$
\mathbb{P}_{A T}=\left\{\mathcal{P}_{a_{1}}, \mathcal{P}_{a_{2}}, \mathcal{P}_{a_{3}}\right\}
$$

where

$$
\begin{gathered}
\mathcal{P}_{a_{1}}=\left\{\left\{x_{1}, x_{4}\right\},\left\{x_{2}, x_{3}, x_{5}\right\},\left\{x_{6}, x_{7}\right\},\left\{x_{8}\right\}\right\}, \\
\mathcal{P}_{a_{2}}=\left\{\left\{x_{1}, x_{4}\right\},\left\{x_{2}, x_{5}\right\},\left\{x_{3}\right\},\left\{x_{6}\right\},\left\{x_{7}\right\},\left\{x_{8}\right\}\right\}, \\
\mathcal{P}_{a_{3}}=\left\{\left\{x_{1}, x_{3}, x_{4}\right\},\left\{x_{2}, x_{5}, x_{7}\right\},\left\{x_{6}, x_{8}\right\}\right\} . \\
\mathbb{C}_{A T}=\left\{C_{a_{1}}, C_{a_{2}}, C_{a_{3}}\right\}
\end{gathered}
$$

where

$$
\begin{gathered}
\mathcal{C}_{a_{1}}=\left\{\left\{x_{1}, x_{4}\right\},\left\{x_{2}, x_{3}, x_{5}\right\},\left\{x_{6}, x_{7}\right\},\left\{x_{8}\right\},\left\{x_{6}, x_{7}, x_{8}\right\}\right\}, \\
\left.C_{a_{2}}=\left\{\left\{x_{1}, x_{4}\right\},\left\{x_{2}, x_{5}\right\},\left\{x_{3}\right\},\left\{x_{6}\right\},\left\{x_{7}\right\},\left\{x_{8}\right\},\left\{x_{3}, x_{6}, x_{7}\right\},\left\{x_{2}, x_{3}, x_{5}\right\},\left\{x_{1}, x_{4}, x_{6}, x_{7}, x_{8}\right\}\right\}\right\}, \\
C_{a_{3}}=\left\{\left\{x_{1}, x_{3}, x_{4}\right\},\left\{x_{2}, x_{5}, x_{7}\right\},\left\{x_{6}, x_{8}\right\},\left\{x_{2}, x_{5}, x_{6}, x_{7}, x_{8}\right\}\right\} .
\end{gathered}
$$

Clearly, $a_{1} \in A T$ is an intersection reducible attribute of $A T$ with respect to $\mathbb{C}_{A T}$, but $a_{1} \in A T$ is not the intersection reducible attribute of $A T$ with respect to $\mathbb{P}_{A T}$.

According to the above two examples, we know that there is no inevitable relationship between the intersection reducible attribute of $A T$ with respect to $\mathbb{C}_{A T}$ and $\mathbb{P}_{A T}$.

From Propositions 5.8-5.11, and Examples 5.4 and 5.5 the relationship among all kinds of reducible attributes based on different granular structures is deeply explored. Next, a figure is used to show the relationship among these reducible attributes.

Figure 3. The relationship among the reducible attributes in the set-valued information system

\section{Conclusion}

Binary information system, multi-valued information system and set-valued information system are three kinds of important information systems which are often used in data mining and knowledge discovery. When these information systems are processed by granular computing method, four kinds of granular structures can be obtained, which are one partition, one covering, multiple partitions and multiple coverings, respectively. For a long time, the researches on these granular structures and their corresponding granular computing models have been carried out independently. In many models of granular computing, we take rough set as an example to compare and study the relationship among these rough set models. In addition, the reduction theories of these granular structures are also discussed. In this paper, we compare the induced granular structure in the same information system, the relationship among the rough 
set models defined by these granular structures and the relationship among the reducts of these granular structures. This paper aims to study the relationship between different rough set models induced from the same information system, so that different rough set theories can be integrated and learn from each other. It is of great significance to improve the ability of data mining and information processing.

Due to the length of the manuscript, this paper only makes a preliminary discussion on the comparative study of different rough set theories, and there are still many problems to be further studied. For example, we can study the measurements and information entropies among these granular structures, the algebraic properties and topological properties of the rough set models defined by these granular structures and so on. Meanwhile, in addition to the rough set model studied in this paper, based on the theoretical development and practical needs, many other rough set models have been proposed, and the relationship between these models still needs to be studied. we can also consider the granular structures induced by the information system in fuzzy environment, and the relationship among granular computing models based on these granular structures. And different rough set models can also be compared in rule extraction. All of these works are worthy of further study.

\section{Acknowledgement}

This work is partially supported by the National Natural Science Foundation of China (Nos. 61976254, 61772002), the central special key projects of basic scientific research fees in Colleges and Universities (XDJK2019B029), the Macau Science and Technology Development Foundation (No. 081/2015/A3), the National Natural Science Foundation of CQ CSTC (No. cstc2015jcyjA40053), the Science and Technology Research Program of Chongqing Municipal Education Commission (Grant No. KJ1709221), and the Natural Science Foundation of Fujian Province (Nos. 2020J01707, 2020J01710), National Foundation Cultivation Program of Jimei University (No. ZP2020063).

\section{Compliance with Ethical Standards}

Conflict of Interest: Author Qingzhao Kong declares that he has no conflict of interest. Author Weihua Xu declares that he has no conflict of interest. Author Dongxiao Zhang declares that he has no conflict of interest.

Ethical approval: This article does not contain any studies with human participants or animals performed by any of the authors.

\section{References}

\section{References}

An JJ, Wang GY, Wu Y, Gan Q (2005) A rule generation algorithm based on granular computing. 2005 IEEE International Conference on Granular Computing. Beijing

Hobbs J (1985) Granularity, Proceedings of the Ninth International Joint Conference on Artificial Intelligence. Los Angeles, CA

Kong QZ, Xu WH (2018) Operation properties and algebraic application of covering rough sets. Fundam Inform 160:385-408

Kong QZ, Xu WH (2019) The comparative study of covering rough sets and multi-granulation rough sets. Soft Comput 23:3237-3251

Kong QZ, Zhang XW, Xu WH, Xie ST (2020) Attribute reducts of multi-granulation information system, Artif Intell Rev 53(2): 1353-1371

Li DY, Meng HJ, Shi XM (1995) Subordinate cloud and subordinate cloud generator. J Comput Res Dev 6:15-20

Li JH, Ren Y, Mei CL, Qian YH, Yang XB (2016) A comparative study of multigranulation rough sets and concept lattices via rule acquisition. Knowl-Based Syst 91:152-164

Li ZW, Zhang PF, Ge X, Xie NX, Zhang GQ, Wen CF (2019) Uncertainty measurement for a fuzzy relation information system. IEEE T Fuzzy Syst 27(12):2338-2352

Li ZW, Liu XF, Dai JH, Chen JL, Fujita H (2020) Measure of uncertainty based on Gaussian kernel for a fully fuzzy information system. Knowl-Based Syst 196, 105791

Li ZW, Huang D, Liu XF, Xie NX, Zhang GQ (2020) Information structrues in a covering information system. Inf Sci 507:449471

Lin TY (2000) Data mining and machine oriented modeling: a granular computing approach. Appl Intell 13(2):113-124 
Lin GP, Liang JY, Qian YH (2013) Multigranulation rough sets: From partition to covering. Inf Sci 241:101-118

Liu CH, Miao DQ, Qian J (2014) On multi-granulation covering rough sets. Int J Approx Reason 55(6):1404-1418

Long BH, Xu WH, Zhang XY, Yang L (2020) The dynamic update method of attribute-induced three-way granular concept in formal contexts. Int J Approx Reason https://doi.org/10.1016/j.ijar.2019.12.014

Pawlak Z (1981) Information systems, theoretical foundations. Inform Syst 6:205-218

Pawlak Z (1982) Rough sets. Int J Comput Inf Sci 11:341-356

Qian YH, Liang JY, Yao YY, Dang CY (2010a) MGRS: A multi-granulation set. Inf Sci 180:949-970

Qian YH, Liang JY, Dang CY (2010b) Incomplete multigranulation rough set. IEEE T Syst Man Cy A 20:420-431

Qian YH, Zhang H, Sang YL, Liang JY (2014) Multigranulation decision-theoretic rough sets. Int J Approx Reason 55(1):225237

Sun L, Wang LY, Ding WP, Qian YH, Xu JC (2019) Neighborhood multigranulation rough sets-based attribute reduction using Lebesgue and entropy measures in incomplete neighborhood decision systems. Knowl-Based Syst https://doi.org/10. 1016/j.knosys.2019.105373

Wang CZ, Shao MW, Sun BQ, Hu QH (2015) An improved attribute reduction scheme with covering based rough sets. Appl Soft Comput 26:235-243

Wang CZ, Wang Y, Shao MW, Qian YH, Chen DG (2020) Fuzzy rough attribute reduction for categorical data. IEEE T Fuzzy Syst 28(5):818-830

Xu WH, Zhang WX (2007) Measuring roughness of generalized rough sets induced by a covering. Fuzzy Set Syst 158(22):24 43-2455

Xu WH, Guo YT (2016) Generalized multigranulation double-quantitative decision-theoretic rough set. Knowl-Based Syst 105:190-205

Xu WH, Yu JH (2017) A novel approach to information fusion in multi-source datasets: A granular computing viewpoint. Inf Sci 378:410-423

Xu WH, Li WT (2016) Granular computing approach to two-way learning based on formal concept analysis in fuzzy datasets.

IEEE Transactions on Cybernetics. 46(2): 366-379

Yang L, Xu WH, Zhang XY, Sang BB (2020) Multi-granulation method for information fusion in multi-source decision information system. Int J Approx Reason 122:47-65

Yao YY (1998) Relational interpretations of neighborhood operators and rough set approximation operators. Inf Sci 111:239259

Yao YY (2001) Information granulation and rough set approximation. Int J Intell Syst 16(1):87-104

Yao YY (2010) Three-way decisions with probabilistic rough sets. Inf Sci 180:341-353

Yao YY (2012) An outline of a theory of three-way decisions. in: RSCTC 2012, LNCS (LNAI) vol. 7413, pp. 1-17

Yao YY (2016) Three-way decisions and cognitive computing. Cogn Comput 8:543-554

Yao YY (2018) Three-way decision and granular computing. Int J Approx Reason 103:107-123

Zadeh LA (1979) Fuzzy Sets and Information Granularity. In: Gupta, N., Ragade, R. and Yager, R., Eds., Advances in Fuzzy Set Theory and Applications, World Science Publishing, Amsterdam, 3-18

Zakowski W (1983) Approximations in the space $(u, \pi)$. Demonstr Math 16: 761-769

Zhang B, Zhang L (1992) Theory and applications of problem solving. Amsterdam: North-Holland Publishing

Zhang XW, Kong QZ (2016) On four types of multi-covering rough sets. Fundam. Inform 147:457-476

Zhu W, Wang FY (2012) The fourth type of covering-based rough sets. Inf Sci 201:80-92 